BANCA D'ITALIA

E U R O S I S T E M A

Questioni di Economia e Finanza

(Occasional Papers)

Robots and employment: evidence from ttaly

by Davide Dottori 

BANCA D'ITALIA

E U R O S I S T E MA

\section{Questioni di Economia e Finanza}

(Occasional Papers)

Robots and employment:

evidence from Italy

by Davide Dottori

Number 572 - July 2020 
The series Occasional Papers presents studies and documents on issues pertaining to the institutional tasks of the Bank of Italy and the Eurosystem. The Occasional Papers appear alongside the Working Papers series which are specifically aimed at providing original contributions to economic research.

The Occasional Papers include studies conducted within the Bank of Italy, sometimes in cooperation with the Eurosystem or other institutions. The views expressed in the studies are those of the authors and do not involve the responsibility of the institutions to which they belong.

The series is available online at www.bancaditalia.it.

ISSN $1972-6627$ (print)

ISSN 1972-6643 (online)

Printed by the Printing and Publishing Division of the Bank of Italy 


\title{
ROBOTS AND EMPLOYMENT: EVIDENCE FROM ITALY
}

\author{
by Davide Dottori*
}

\begin{abstract}
Increased robot diffusion has raised concerns for its possible negative impact on employment. Following an empirical approach in line with those applied to the US and Germany with contrasting results, this paper provides evidence about the effect of robots on employment outcomes in Italy (second European economy for robot stock) from the early 1990s up to 2016, both at the local labour market (LLM) level and at the worker level. In order to purge from demand and other confounding shocks, the identification relies on an instrumental variables strategy based on robots' sectoral growth in other European countries. No harmful impact on total employment emerges from the LLM analysis; the estimated effect is negative when limited to manufacturing employment, but its statistical significance is weak or absent once concurrent trends relating to trade and ICT are controlled for. Results at the worker level show that incumbent workers in manufacturing were not damaged on average, with an overall positive (though not large) employment effect, driven by longer working relationships with the original firm; conditional on them remaining at the original firm, the impact is also positive on wages. On the other hand, robot diffusion turns out to have contributed to reshaping the sectoral distribution of the new labour force inflows towards less robot intensive industries.
\end{abstract}

JEL Classification: J23, J31, L11, L60, O33, R11.

Keywords: robot, automation, employment, wages, local labour markets.

DOI: $10.32057 / 0$. QEF.2020.572

\section{Contents}

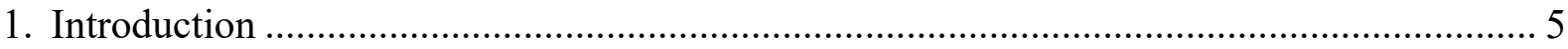

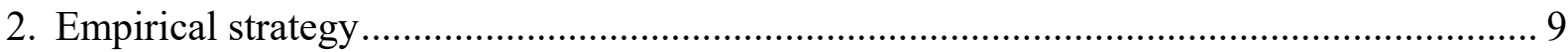

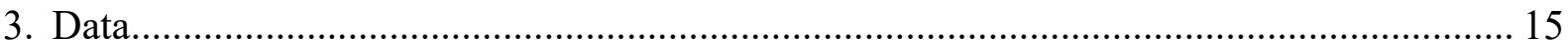

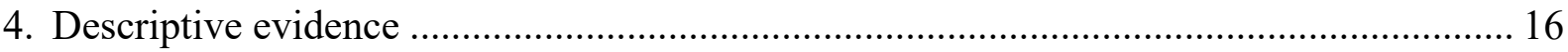

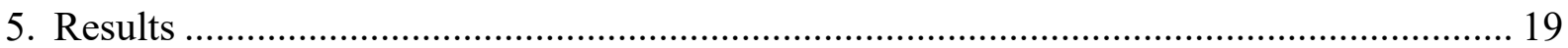

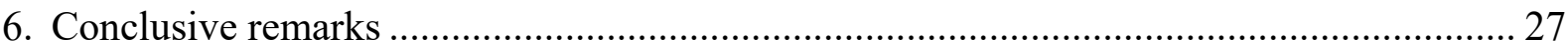

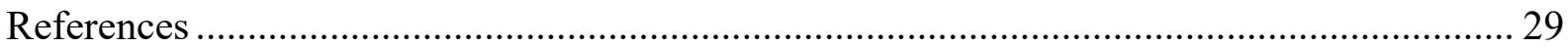

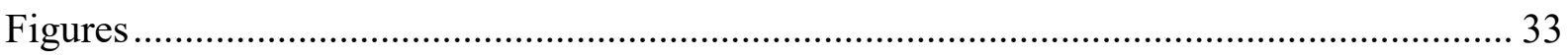

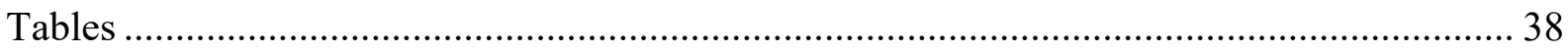

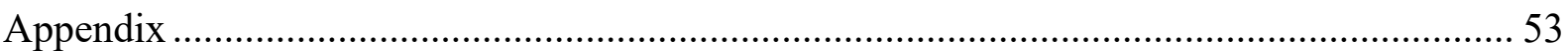

\footnotetext{
* Banca d'Italia, Ancona regional branch, Local Economic Research and Analysis Division.

The author would like to thank Emanuele Ciani and Eliana Viviano for their suggestions and help throughout the preparation of this work. Thanks for very useful comments, hints and clarifications on data go to Gaetano Basso, Alessandro Borin, Giulia Bovini, Francesca Carta, Emanuela Ciapanna, Luca Citino, Marta De Philippis, Federico Giorgi, Andrea Linarello, Michele Mancini, Andrea Petrella, Paolo Sestito and all participants in a seminar at the Bank of Italy. All remaining errors are of course the author's sole responsibility. The views in this paper are those of the author and do not necessarily reflect those of the Bank of Italy.
} 



\section{Introduction*}

Developments in robotics and other forms of automation have raised concerns that, by replacing labour in production, workers could be laid off and overall employment reduced. According to a survey by European Commission (2017), more than 70 per cent of Europeans believe that 'robots and artificial intelligence steal peoples's jobs'. Even though the topic of job displacement following technological progress is anything but new in economics (Keynes, 1930; Leontief, 1952) ${ }^{1}$ and these concerns have not materialized so far in the long run (Bessen et al., 2020), there are worries that things could be different this time as the next waves of automation will occur at unprecedented rates on comparable scales (Dobbs et al., 2015; Frey and Osborne, 2017). ${ }^{2}$

From a theoretical point of view, however, the impact of robots on employment is not clear $a$ priori as it involves forces moving in opposite directions (Acemoglu and Autor, 2011; Acemoglu and Restrepo, 2018): if on the one hand, for certain tasks robot technology is first-order laboursaving in certain tasks, on the other hand, it can enhance productivity, reduce prices and thereby increase demand. In addition, demand-enhancing effects may extend to other connected markets for goods and services (Dosi et al., 2019; Barbieri et al., 2019); the introduction of robots may also increase the demand for complementary non-automatable tasks (Autor, 2015) or even create new tasks (Acemoglu and Restrepo, 2019). ${ }^{3}$

Whether the net effect of robots on employment is positive, neutral or negative is thus essentially an empirical issue. In this paper this question is addressed for the case of Italy following approaches used in two previous researches that focused on the US (Acemoglu and Restrepo, 2017) and on Germany (Dauth et al., 2018), finding contrasting results. Acemoglu and Restrepo (2017) find that the displacement effect prevails as commuting zones more exposed to robots end up with worse outcomes, in terms of both employment and wages. Conversely, Dauth et al. (2018) find no effect on overall employment in Germany since the negative effect emerging in manufacturing turns out to be fully compensated by the positive effect in other sectors.

Against this background, Italy is an interesting case to enrich the evidence available as the use of robots in this country is neither negligible nor new. Indeed, Italy has been steadily ranked sec-

${ }^{*}$ The author would like to thank Emanuele Ciani and Eliana Viviano for their suggestions and help throughout the preparation of this work. Thanks for very useful comments, hints and clarifications on data go to Gaetano Basso, Alessandro Borin, Giulia Bovini, Francesca Carta, Emanuela Ciapanna, Luca Citino, Marta De Philippis, Federico Giorgi, Andrea Linarello, Michele Mancini, Andrea Petrella, Paolo Sestito and all participants in a seminar at the Bank of Italy. All remaining errors are of course the author's sole responsibility. The views in this paper are those of the author and do not necessarily reflect those of the Bank of Italy.

${ }^{1}$ Keynes (1930) discussed the concept of technological unemployment defining it as 'unemployment due to our discovery of means of economising the use of labour outrunning the pace at which I can find new uses for labour', which however he rated to be 'only a temporary phase of maladjustment'. Leontief (1952) expressed a more pessimistic view: 'Labour will become less and less important [... ] More and more workers will be replaced by machines. I do not see that new industries can employ everybody who wants a job'. Broadly speaking, the interest in the consequences for employment of new machines could be traced back to Ricardo (1821). See Mokyr et al. (2015) for a survey on concerns about technological changes and their socioeconomic impacts.

${ }^{2}$ Frey and Osborne (2017) estimate that almost 50 per cent of all workers in the US could be replaced by machines. While such a size is not undisputed (Arntz et al., 2016), it is generally recognized that there is already the potential to automate a considerable amount of tasks: according to MGI (2017), about 60 per cent of occupations have at least 30 per cent technically automatable activities with currently demonstrated technologies.

${ }^{3}$ Moreover, it has to be considered that robots are typically used to perform particular tasks that do not necessarily comprehend all the tasks embedded in a job (Bessen et al., 2020). 
ond after Germany among European countries since the early 1990s for operational stock of robots (IFR, 2018). To the best of my knowledge, this is the first study to address the long-term impact of robots on employment specifically in Italy. Previously, Italy was included in some cross-country studies (Chiacchio et al., 2018; Graetz and Michaels, 2018) but, as suggested by the contrasting evidence found by Acemoglu and Restrepo (2018) and Dauth et al. (2018), the employment effect of robots might be country-specific (Gentili et al., 2020).

Following the approach developed by Acemoglu and Restrepo (2017), the first part of the analysis adopts a local-level perspective to assess whether local labour markets (LLM) experienced different employment dynamics between 1991 and 2016 depending on their different exposure to robots. This perspective takes into account that the impact of robots is uneven within a country (OECD, 2018): since industries are not uniformly localized within a country and as they differ in how much they can automatize production, the impact of robot diffusion could be asymmetric not only across sectors but also across regions, with significant policy implications for the labour market, income distribution and regional development. ${ }^{4}$ Moreover, the local-level analysis allows to spillover and indirect general equilibrium effects to be embedded, thus being informative about the ultimate net effect. The LLM exposure to robots is measured by exploiting heterogeneity in robot use across industries and heterogeneity in the initial industry distribution of local employment: specifically, the exposure is given by a weighted average of the robot diffusion by industry with weights equal to the initial share of each industry in the local employment.

The estimation strategy takes into account that the variation in the number of robots may be endogenous to demand shocks also affecting employment, and that it can be correlated with concurrent trends that may impact employment evolution or its distribution across industries. In particular, these issues are tackled by taking advantage of information on robot use in other advanced European countries to construct instrumental variables. This is aimed at capturing supply-side and technological factors, while purging from demand and place-specific factors. In addition, following Dauth et al. (2018), two important macro trends occurring in the period - such as the increasing trade with China and Eastern Europe (Autor et al., 2013) and the diffusion of ICT technology - are controlled for, as well as the initial differences in the stage of the structural change process relating to the diminishing long-term trend in the employment share of manufacturing (Wren, 2013). Similarly to Dauth et al. (2018), no evidence emerges of a systematic and statistically significant impact of higher robot exposure on overall employment growth, nor on the change in the employment to population ratio. When employment is split between manufacturing and other sectors, the coefficient for manufacturing employment is negative, but its statistical significance is not strong, especially when the concurrent trade and ICT shocks are controlled for. For non-manufacturing employment the effect is largely insignificant.

In the second part of the analysis, I follow Dauth et al. (2018) more closely and complement the evidence with worker-level data form matched employer-employee administrative data. At first the focus is on incumbent workers (i.e.: workers that were initially employed) in manufacturing and on their employment outcomes in terms of cumulated days worked, cumulated earnings and

\footnotetext{
${ }^{4}$ The analysis was taken to an even more detailed geographical level by Frank et al. (2018) by focusing on urban areas: they find that in the US, smaller cities are subject to higher job substitution and worker displacement following automation.
} 
average wages in the following 23 years. Compared with the local level approach, which cannot say anything about adjustment to robots at the individual level, this approach allows to track how career patterns respond to robot exposure. In this case, the identification exploits industry heterogeneity in robot exposure, after netting out confounding effects relating to observable characteristics of workers, firms and geographical areas. Heterogeneous effects with respect to gender, age, area, initial earnings and occupation are also explored.

The results show - again in line with Dauth et al. (2018) - that workers in industries with higher robot exposure ended up being employed for longer, although the effect is small from an economic point of view. This translates into higher cumulated earnings, while the effect on average wages is not statistically different from zero. These positive impacts are driven by outcomes at the original firm, for which the positive effect also extends to wages, though its size is not economically high. ${ }^{5}$ Conditional on leaving the original employer, the employment effect is negative (though modest) and a positive wage effect only emerges for workers remaining in the original industry. An interpretation of these results could be based on the existence of firm-specific complementarities between workers' on-the-job experience and the implementation of robots in the process of production, so that being in a sector that is more exposed to robots may positively affect the duration of the relationship with the same firm. ${ }^{6}$

The third part of the analysis deals with the issue of how robot exposure has affected the inflows of new workers. Worker-level data and the LLM-level approach are combined to construct a measure of the likelihood of entering a sector at the LLM level, and how it changed between 1993 and 2016. The results show that relative inflows have been systematically lower in areas and industries more exposed to robots. This suggests that an employment effect of robots could have worked through a contribution to the redistribution of the new labour force across sectors. As robot exposure is higher in manufacturing, these findings are reconciled with the evidence of a relatively more negative effect on manufacturing employment found in the first part. Based on these estimates, robot exposure could account for about one fifth of the decrease in the manufacturing share of new workers' inflows.

All in all, this evidence draws a picture more similar to Germany than to the US for Italy, since the results are more in line with the less pessimistic ones in Dauth et al. (2018), rather than with the displacement effects found by Acemoglu and Restrepo (2017). This could also be related to the higher similarity of the Italian economy to Germany rather than to that of the US, in terms of institutional settings (with higher employment protection), economic structure (with a relatively higher weight of manufacturing) and the sectoral distribution of robots, more prevalently used in mature sectors and less in electronics (as shown in Section 4). These results are also in line with the (non-causal) evidence recently provided by Klenert et al. (2020) of a non-negative relationship between robots and employment in 14 European countries (including Italy). ${ }^{7}$ While this evidence

\footnotetext{
${ }^{5}$ The findings on wages are partly different from Dauth et al. (2018) as they find a negative general effect on wages, that improves at the original firm becoming statistically non-significant. I similarly find a better outcome at the original firm but with a positive effect at the original firm and a non-significant general effect.

${ }^{6}$ At the same time, there may be industry-specific complementarities between robots and labour so that changing employers in the same industry may be associated with lower employment due to time frictions before matching a new employer in the industry but also higher wages once a job is found. See Section 5.2.

${ }^{7}$ Klenert et al. (2020) show that this holds for low-skilled workers as well. This would also be consistent with the
} 
is not necessarily informative for the upcoming years, especially if the use of robots undergoes an acceleration, it is at least reassuring as regards its impact so far.

Besides Acemoglu and Restrepo (2017) and Dauth et al. (2018), this paper relates to other studies based on robot data provided by the International Federation of Robotics (IFR) in a cross-country framework. Graetz and Michaels (2018), while focusing mainly on the effect of robots on productivity, found that robot density had no significant effect on aggregate hours worked and a negative effect only for the low-skilled workers. ${ }^{8}$ Chiacchio et al. (2018), based on regional data from six European countries including Italy, estimate a negative effect of robots on the employment rate, while no significant effect is found for wages; the estimated magnitude of the impact is lower than in Acemoglu and Restrepo (2017) and the authors connect this attenuation to the higher employment protection in Europe. As in Graetz and Michaels (2018), the analysis stops in 2007, also because of structural breaks due to sector reclassifications. As Dauth et al. (2018), the present paper extends the analysed period up until recent years, as advocated by Barbieri et al. (2019), by adopting a cross-walk for industry classifications that remains consistent both internally and with the IFR industry categories.

Evidence for recent years at international level is provided by Chen and Nabar (2018) and Carbonero et al. (2018). Chen and Nabar (2018) find a negative relationship between robots and employment from 2010 to 2014 for advanced countries that experienced higher output losses during the economic crisis. Conversely, Carbonero et al. (2018) find a more negative impact for emerging economies, associated with a reduction in off-shoring for advanced countries. Using industrystate-year observations in the US, Borjas and Freeman (2019) compare the employment and wage effects of robots with those of immigration flows. Though measuring robot exposure differently from Acemoglu and Restrepo (2017), ${ }^{9}$ they confirm a negative impact of robots on US employment. $^{10}$

As IFR data are aggregated at industry and national level, a recent stream of literature has looked to other sources in order to find information on robot use at the firm level, as advocated by Raj and Seamans (2019). In particular, firm-level data have been taken from survey data (Koch et al., 2019; Bessen et al., 2019), fiscal and administrative data (Acemoglu et al., 2020) or they were derived from proxies such as imports (Dixon et al., 2019; Bonfiglioli et al., 2019) or electricity consumption for motor power (Aghion et al., 2020). The results are mixed: Bonfiglioli et al. (2019) and Bessen et al. (2019) find negative effects on firm employment once the spurious positive correlation induced by demand effects is netted out. On the other hand, Dixon et al. (2019) for Canada and Koch et al. (2019) for Spain find a positive impact for firms introducing robots. Koch et al. (2019) also find a negative effect on competing non-adopting firms; Acemoglu et al. (2020) for France obtain similarly contrasting results between adopters and non-adopters but with prevailing negative

results for blue-collar workers reported in Section 5.2.

${ }^{8}$ In this respect, this result contrasts with the polarization effect found in other research on ICT technology (Goos et al., 2014; Goos and Manning, 2007; Autor, 2014). In Graetz and Michaels (2018), the exposure to robots and the identification of its effects are connected to the concept of replaceability, according to a classification of occupation tasks and robot applications.

${ }^{9}$ Borjas and Freeman (2019) build robot stocks starting from flows and assuming in the baseline specification that the rate of depreciation and the rate of appreciation due to quality improvements balance each other out.

${ }^{10}$ Compared with migration, the marginal effect of an additional robot per worker is found to be stronger but its aggregate impact was still modest due to the lower increase in robots. 
effects, a finding in contrast with the net positive effect found for the same country by Aghion et al. (2020).

The remainder of the paper proceeds as follows: in Section 2 the empirical strategy is presented and discussed; Section 3 describes the data and how they are implemented into the analysis; Section 4 provides a descriptive analysis about robots in Italy, also in comparison with other countries; in Section 5, results are shown and commented and organized into three subsections for the analysis of local employment, incumbent workers and entrant shares respectively. Finally, Section 6 concludes.

\section{Empirical strategy}

\subsection{Local level analysis}

The unit of analysis for the effect of robot exposure on employment at the local level is the local labour market (LLM), defined according to the National Statistical Institute. This definition takes into account commuting ties among municipalities, thus being comparable with the concept of commuting zones in the US. ${ }^{11}$ The classification can vary over time, also because of evolutions in commuting patterns. Since commuting patterns in turn depend on economic activity and given that the base year for employment and population data is 1991 (see Section 3), the 1991 definition of LLMs is used; subsequent definitions might be endogenous as influenced by shocks under analysis. According to the 1991 classification in Italy there were 784 LLMs; for comparison, in their baseline specification Dauth et al. (2018) consider 402 local labour markets in Germany in 1994, Acemoglu and Restrepo (2017) base their analysis on 722 commuting zones.

The baseline model can be specified as follows:

$$
\Delta y_{r}=\alpha^{\prime} x_{r}+\beta \Delta r o b_{r}^{I T}+\gamma \Delta \operatorname{trade}_{r}^{I T}+\delta \Delta i c t_{r}^{I T}+\phi A R E A_{r}+\epsilon_{r}
$$

where the subscript $r$ refers to the LLM. The dependent variable $\Delta y_{r}$ is either employment growth (proxied by log differences) or the difference in the employment to working age population ratio. As done in the reference literature, a long-term perspective is taken and changes are measured as long differences; this also allows to reduce the relevance of the measurement error. The initial year for employment and population data is 1991, while the ending year is $2016 .{ }^{12}$ At first, the effect is assessed on total employment and then on manufacturing and non-manufacturing employment separately.

The variable $\Delta r o b_{r}^{I T}$ measures the robot exposure with $\beta$ representing the parameter of interest. Variables $\Delta$ trade ${ }_{r}^{I T}$ and $\Delta i c t_{r}^{I T}$ control for the concurrent effects relating to, respectively, trade with China and Eastern Europe and to ICT diffusion. The vector $\boldsymbol{x}_{r}$ includes a set of control variables in 1991 to allow for possible different trends across LLMs depending on their socio-demographic structure: share of female population, share of foreign born population, share of graduated people, share of people with high school degree, share of population elder than 50 years. The share of

\footnotetext{
${ }^{11}$ See Coppola and Mazzotta (2005) for further details.

${ }^{12}$ Shorter time intervals are also considered; see Section 5.1.
} 
employment in manufacturing is also included in $x_{r}$ : it is important to add this control because robots are mainly used in the manufacturing sector, so differences in the initial manufacturing share introduce an initial cross-sectional variation in robot exposure. Macro-area dummies (NorthEast, Center and South, with North-West as the reference category) are included too. ${ }^{13}$

The first issue in estimating $\beta$ is that ideally one would like to observe robot use at the local level, but IFR data are available only at the industry level for the whole country. Following Dauth et al. (2018) and Acemoglu and Restrepo (2017), I consider a measure of local exposure to robots that weights the increase of robots in each industry by the initial industry share out of total local employment: ${ }^{14}$

$$
\Delta r o b_{r}^{I T}=\sum_{j=1}^{J} \frac{e m p 1991_{j r}}{e m p 1991_{r}} \times \frac{\Delta \text { ROBOTS }_{j}^{I T}}{e m p 1991_{j}} \times 1000
$$

where $\triangle R O B O T S_{j}^{I T}$ is the variation in robot operational stocks in industry $j$ at national level, with $j$ defined according to the IFR classification (see Section 3). ${ }^{15}$ The initial employment in the industry at the national level emp $1991_{j}$ is used to normalize the number of robots across industries. The exposure to robots is thus essentially a Bartik-style measure which combines industry-level variation in the usage of robots and baseline employment shares.

The possibility of identifying a causal impact of robot exposure on employment dynamics is challenged by endogeneity concerns that may arise from a spurious correlation due to an omitted variable bias. An example is provided by demand factors that may induce a positive correlation between the use of robots and employment; a spurious correlation may also emerge from placespecific shocks that affect both the employment dynamics and the LLM exposure to robots. A non-causal relationship could be driven also by the presence of on-going long run trends that happen to be correlated with robot exposure: for example, if manufacturing features a long run decreasing trend, the fact that robot are typically used more in manufacturing may introduce a negative non-causal correlation; this is a further reason to control for initial manufacturing shares. Moreover, since the robot exposure variable uses initial industry shares, problems to identification arise if these shares are endogenous to the overall employment change between 1991 and 2016. Endogeneity may possibly come also in terms of reverse causation from employment growth to robot diffusion if, for example, the employment growth had effects on labour costs and in turn on the incentive for firms to substitute labour with robots. ${ }^{16}$

As in Dauth et al. (2018), endogeneity issues are addressed by implementing a (overidentified) 2SLS estimator where exposure to robots is instrumented using information on the sectoral

\footnotetext{
${ }^{13}$ As a robustness check, more granular regional dummy variables are used: see Section 5.1.

${ }^{14}$ Acemoglu and Restrepo (2017) provide a theoretical model microfounding this choice in a general equilibrium framework where there is trade across commuting zones and they use a slightly different specification of robot exposure that directly follows from their theoretical model. However, they show that their results are substantially unaffected by using a simpler specification analogous to Eq. (2), which is also the measure adopted by Dauth et al. (2018).

${ }^{15}$ So, for example, the exposure to robot for the LLM $r$ is given by the weighted sum of the change in the robot stock between 1993 (the first year available in the data source) and 2016 in the IFR industries with weights equal to the industries' employment share in 1991.

${ }^{16}$ It is fair to acknowledge that also issues of measurement error and attenuation bias may arise. This is actually a common issue to all the literature using this identification strategy and it inevitably follows from the lack of data on robots at the firm level.
} 
increase of robots in other advanced European countries. ${ }^{17}$ The aim of this strategy is to isolate the exogenous supply factors due to technological advances, common to other countries, purging from confounding factors like demand shocks or place-specific shocks that may be correlated with changes in employment through other channels. ${ }^{18}$ I consider the following countries as in Dauth et al. (2018): France, Spain, Finland, Denmark, Sweden, Norway, United Kingdom, to which I add Germany instead of Italy. For each country $C$ the instrument is built as follows:

$$
\Delta r o b_{r}^{C}=\sum_{j=1}^{J} \frac{e m p 1981_{j r}}{e m p 1981_{r}} \times \frac{\Delta \text { ROBOTS }_{j}^{C}}{e m p 1981_{j}} \times 1000
$$

Note that the absolute variation in robot utilization $\triangle R O B O T S_{j}^{C}$ is normalized by Italian employment in industry $j$ in 1981 and employment shares are taken in 1981. The use of 1981 in the instrument instead of 1991 is aimed at further limiting the endogeneity concerns described above. In this way differences in LLM's industrial specialization predate changes in robotics technology under analysis. As remarked by Acemoglu and Restrepo (2017), this choice also contribute to curbing issues of mechanical correlation or mean reversion associated with changes in industry employment in anticipation of the subsequent introduction of robots.

In order to be valid, instruments have to show a good explicative power and they must not be related with the dependent variable through channels different from their effect on the endogenous variable. The former property can be supported by results and statistics from the first stage regression, while the latter assumption cannot be directly tested but, as commonly done in the literature, some evidence of no pre-trend effects can be provided: should the robot exposure be correlated with previous employment changes, the reliability of the identification strategy would be hindered by the suspect that any correlation with the current trend is spurious, because associated to employment dynamics that were already going on. Other sources of bias that may be revealed by pre-trend effects are selection (i.e. LLM employment could have adjusted in advance in anticipation of robot use) and other omitted variables (place specific factors were not properly controlled for). In Section 5.1 evidence in support of the reliability of the estimation strategy is provided.

Moreover, as the exclusion restriction requires that robot installations in those other countries have no direct impact on Italian LLMs, worries may arise that this assumption is less likely to hold for countries to which Italy is more connected, for example if in some LLMs workers were employed to produce complementary (or substitutive) goods for closely-linked foreign partners. To address this issue, in Section 5.1 a robustness check excludes from the pool of instruments countries belonging to the Euro Area and also estimates the model using country instruments one by one.

Another challenge to identification is posed by possible contemporaneous relevant macroeconomic shocks that may confound the genuine effect of robots. In particular, as in Dauth et al. (2018), two concurrent macro trends are considered, i.e.: the rising trade with China and Eastern

\footnotetext{
${ }^{17}$ Exactly identified 2SLS is also considered by taking the instruments based on other countries data one by one. See Section 5.1.

${ }^{18}$ A similar stategy is used in several studies addressing the effects of Chinese competition, e.g.: Autor et al. (2013), Bloom et al. (2016) and, for the Italian case, Citino and Linarello (2019).
} 
European countries and the diffusion of ICT technology. Therefore, model (1) includes $\Delta$ trade $e_{r}^{I T}$ and $\Delta i c t_{r}^{I T}$ as control variables. They are defined as follows:

$$
\begin{aligned}
\Delta \text { trade }_{r}^{I T} & =\sum_{j=1}^{J} \frac{e m p 1991_{j r}}{{\text { emp } 1991_{r}}_{1}} \times \frac{\Delta T R A D E_{j}^{I T}}{\text { emp } 1991_{j}} \\
\Delta i c t_{t}^{I T} & =\sum_{k=1}^{J} \frac{e m p 1991_{k r}}{e m p 1991_{r}} \times \frac{\Delta I C T_{k}^{I T}}{e m p 1991_{j}}
\end{aligned}
$$

where $\triangle T R A D E_{j}^{I T}$ is the change in the real net trade (exports minus imports) of goods for Italy vis-à-vis China and Eastern European countries in each IFR industry $j$ (see Section 3). This is an (inverse) measure of the exposure of sector $j$ to the competition of these countries. ${ }^{19}$ Regarding ICT exposure, $\triangle I C T_{k}^{I T}$ is the change in real gross fixed capital formation for computing equipment and communications equipment at the sectoral level according to EU KLEMS data. ${ }^{20}$ As both $\Delta \operatorname{trade}_{t}^{I T}$ and $\Delta i c t_{t}^{I T}$ could be endogenous, similarly to the strategy adopted for robots, the instruments for these variables based on country $C$ data are built as:

$$
\begin{aligned}
\Delta \text { trade }_{r}^{C} & =\sum_{j=1}^{J} \frac{e m p 1981_{j r}}{e m p 1981_{r}} \times \frac{\Delta T R A D E_{j}^{C}}{e m p 1981_{j}} \\
\Delta i c t_{r}^{C} & =\sum_{k=1}^{J} \frac{e m p 1981_{k r}}{e m p 1981_{r}} \times \frac{\Delta I C T_{k}^{C}}{e m p 1981_{j}}
\end{aligned}
$$

\subsection{Worker-level analysis on incumbents}

In the second part of the analysis matched employer-employee data from administrative registries are used to assess whether the individual careers of workers initially employed in manufacturing differed according to their industry's exposure to robots. The dataset allows to control for a number of confounding factors related to workers, employers and labour markets characteristics. As in Dauth et al. (2018), Autor et al. (2013) and Citino and Linarello (2019) I take a long-term perspective and consider cumulated labour market outcomes in subsequent years.

The model equation for incumbent workers is the following:

$$
y_{i, j, f, g}=\alpha+\beta_{1} \Delta r o b_{j}^{I T}+\beta_{2} \Delta t r a d e_{j}^{I T}+\beta_{3} \Delta i c t_{k}^{I T}+\gamma^{\prime} x_{i, j, f, g}+\delta f_{f}+\phi g_{g}+\epsilon_{i, j, f, g}
$$

where $i, j, f, g$ referees to characteristics at the worker, sector, firm and geographical level respectively. The exposure to robots is defined at the sectoral level and normalized by the sectoral em-

\footnotetext{
${ }^{19} \mathrm{~A}$ higher (in absolute terms) negative value means that the sector suffered more from the competition of those countries, while a higher positive value indicates a sector which benefited from the opportunity of increased markets in those countries.

${ }^{20}$ The subscript for sector is $k \neq j$ as in EU KLEMS data the industry aggregation is different from the IFR one. See Section 3 for further details.
} 
ployment in 1991, e.g.:

$$
\Delta r o b_{j}^{I T}=\frac{\Delta \text { ROBOTS }_{j}^{I T}}{e m p 1991_{j}} \times 1000
$$

The trade and ICT exposure are defined analogously.

Outcome variables are cumulated days worked, cumulated earnings, and average wages; 1993 is taken as base year given constraints on data availability and taking into account the opportunity to keep some information on workers' background career (see Section 3). ${ }^{21}$ Hence, the period over which working days and earnings are cumulated and the average wage is computed goes from 1994 to 2016. Constraints on age in the base year are imposed to limit the confounding effect of retirements (see Section 3).

The $\mathbf{x}$ covariates include controls for worker $i$ characteristics, such as gender, country of birth and the base year values of the following variables: a coarse code of occupation dummies ("blue collar", "white collar", "apprentice", "manager"), a full set of age dummies, a dummy for tenure lower than 4 year, a dummy for part-time status, log earnings and days worked in that year. Controls at the firm level $f$ are a set of dummies for firm size (based on the average number of employees in the base year: less than 20, between 20 and 249, equal to or more than 250). Controls at geographic level $g$ include region fixed effects (for the firm and the working region, if different), unemployment rate and employment rate in the working province in the base year.

Similarly to what discussed in Section 2.1, the variable $\Delta \operatorname{rob}_{j}^{I T}$ might suffer from endogeneity, for example if factors affecting the decision by Italian firms in the sector to use robots may affect also their labour demand (e.g. demand factors). Moreover, when considering wages as outcome, endogeneity may also arise if, for instance, high wages affect the decision to install robots. Hence Eq. (8) is estimated by 2SLS, considering as endogenous the exposures to robots, trade and ict, and instrumenting them with their counterparts based on data for the same set of countries listed in Section 2.1.22 All standard errors are clustered at the IFR sector-province level to control for correlation of disturbances for employees working in the same province and subject to the same robot shock.

In a further step of analysis, outcomes are distinguished according to whether they either occurred at the original firm, or in other firms within the same manufacturing industry, or in other manufacturing industries or else outside of manufacturing. In this way it can be assessed whether the robot exposure has implied displacement at individual level and quantify the possible costs associated to the re-allocation due to market frictions, search costs, and other difficulties of readjustment (Autor et al., 2014). Then the analysis is further enhanced by studying heterogeneous effects with respect to occupation classes, age groups, gender, initial earnings groups, geographical area.

It is important to highlight that in the worker-level analysis, given the set of control variables, it is possible to compare workers with similar observable demographic characteristics, working in similar firms and in similar areas, differing with respect to the robot exposure of their sector. An

\footnotetext{
${ }^{21}$ This base year coincides with the first year for which data on robot stocks are available. To avoid simultaneity issues the robot stock change is again normlaized by employment in the sector in 1991, as shown in Section 2.1.

${ }^{22}$ As in Section 2.1 for the instruments employment shares in the sector in 1981 are used. Trade sectors are defined according to ateco 2007 2-digit codes, while ICT data are based on the less detailed EU KLEMS classification.
} 
individual control that is unfortunately missing in the data is the level of education, thus posing issues related to omitted control for ability (which can only be poorly accounted for by earnings in the base year after netting out factors like tenure and age). Hence, results on differential outcomes between stayers at the original firm and movers may partly reveal also different features of workers, i.e.: stayers and movers may differ with respect to their ability and firms may choose to separate from less able workers. The joint inspection of outcomes in terms of quantities (days) and prices (wages) may however be informative in this respect. ${ }^{23}$

\subsection{Analysis on entrant workers}

In the third part of the analysis, the focus is on entrants and re-entrants workers to assess how robot exposure have affected the sectoral distribution of new employment. ${ }^{24}$ In this part worker-level data and the local-level approach are combined. From the matched employer-employee dataset the share of entrants in each IFR sector out of the total number of entrants is computed for each and every LLM, both in 1993 and in 2016. Then difference in these shares between the two years is taken as dependent variable in the following model:

$$
\Delta s h_{r j}^{w}=\alpha^{\prime} x_{r}+\beta_{1} \Delta r o b_{j r}^{I T}+\beta_{2} \Delta t r a d e_{j r}^{I T}+\beta_{3} \Delta i c t_{r}^{I T}+\phi A R E A_{r}+\epsilon_{r j}^{w}
$$

where $w=$ \{entrants, re-entrants $\}$ and the model equation is analogous to (1) but considering LLM-IFR sector cells, instead of collapsing all data at the LLM level. In particular, the robot exposure and its instrument build from country $C$ data are defined as follows: ${ }^{25}$

$$
\begin{aligned}
\Delta r o b_{j r}^{I T} & =\frac{e m p 1991_{j r}}{e m p 1991_{r}} \times \frac{\Delta \text { ROBOTS }_{j}^{I T}}{e m p 1991_{j}} \\
\Delta r o b_{j r}^{C} & =\frac{e m p 1991_{j r}}{e m p 1991_{r}} \times \frac{\Delta \text { ROBOTS }_{j}^{C}}{e m p 1991_{j}}
\end{aligned}
$$

The model is estimated by 2SLS. Each observation is weighted by the LLM weight in national employment for each sector in 1991. In addition, unweighted 2SLS regressions and OLS regressions are also performed. Standard errors are clustered at LLM level.

\footnotetext{
${ }^{23}$ If, for example, we observe lower days worked associated to lower wages it is arguably less likely that we are observing workers with ability above the average.

${ }^{24}$ Given constraints on data availability, entrants are considered as those workers that did not work for at least 3 years before the observed year and re-entrants are considered as those workers that did not work the year before the observed year but had at least one remunerated job spell in the two previous years. For details see Section 3.

${ }^{25}$ I do the same for the trade variable. For the ICT variable, since it is not possible to do a cross-walk form EU KLEMS to IFR sector groups, I keep this control at the LLM level, built as shown in Eq. (5).
} 


\section{Data}

The variable on robot exposure is based on industrial robot data reported by the International Federation of Robotics (IFR, 2018), as commonly done in the reference literature. ${ }^{26}$ In this data source a robot is defined according to the ISO definition 8373 as an 'automatically controlled, reprogrammable, multi-purpose manipulator programmable in three or more axes, which may be either fixed in place or mobile for use in industrial automation applications'. Robots are hence fully autonomous machines that do not need a human operator and can be programmed to perform several manual tasks such as welding, painting, assembly, handling materials, or packaging.

IFR (2018) collects data on sales and reports measures of the operational stock of robots at the country and industry level (ISIC Rev. 4 codes) from 1993 to 2017 (see Appendix A.1 for further details). The data availability and sectoral details vary with countries and years. As a sufficient temporal depth is needed to carry out the analysis in a long-term perspective, the earliest available year is considered. Besides Italy, data since 1993 are available for Germany, France, Spain, Finland, Denmark, Sweden, Norway, United Kingdom. ${ }^{27}$ The degree of sectoral detail is chosen in such a way to have consistent data across countries and time: the resulting 17 industry groups are reported in Table $1 .^{28}$

Trade data are taken from OECD by extracting exports and imports for 31 sectors by Italy and the eight European countries listed above vis-à-vis China and countries that were part of the former Soviet bloc. The detailed lists of partner countries and sectors are reported in Appendix A.2. Data on ICT equipment are taken from EU KLEMS (Kirsten, 2016; O'Mahony and Timmer, 2009), by collecting data on real (2010 prices) gross fixed capital formation volume for computing equipment and communications equipment. The industry aggregation in EU KLEMS is different from the IFR's one and it is not possible to cross-walk from the former to the latter exactly. Hence, for the ICT variable I keep the EU KLEMS industry classes and map into them the Ateco 2007 codes at the 2-digit level to build the ICT exposure variable as defined in Section 2. Additional details and the list of EU KLEMS industry classes with the resulting ICT exposure can be found in Appendix A.2.

Data sources for employment and population are firm Census data (Censimento generale dell'industria e dei servizi), the Italian Statistical Register of Active Enteprises (Registro statistico delle imprese attive, ASIA), Population Census data provided by Istat (Statistical Atlas of municipalities and other datasets). Appendix A.2 describes more in detail the different data sources for different years and how these sources were merged to create a consistent dataset, in particular with respect to issues of sector reclassifications and changes in the geographical unit of analysis occurred during the period.

Data used in the worker-level analysis come from administrative data collected by the Italian Social Security Institute (INPS). In particular, information on workers is taken form a sample of

\footnotetext{
${ }^{26}$ E.g.: Dauth et al. (2018), Acemoglu and Restrepo (2017), Graetz and Michaels (2018), Borjas and Freeman (2019), Backer et al. (2018).

${ }^{27}$ This is in line with Dauth et al. (2018) and Acemoglu and Restrepo (2017). As reported by Acemoglu and Restrepo (2017), these nine countries accounted for more than two fifths of the whole world market.

${ }^{28}$ The robot stocks in the residual category "unspecified sector" are distributed across other sectors proportionally, following Acemoglu and Restrepo (2017).
} 
privately employed individuals; by means of an employer identifier it is possible to associate firm features taken from another dataset covering the universe of Italian firms year by year, thus creating a matched employer-employee dataset. Further details are provided in Appendix A.3. In the analysis of incumbent workers, the selected sample consists of workers with positive amounts of days worked and earnings in 1993. Following Dauth et al. (2018), the sample is restricted to workers with at least two years tenure and whose age in 1993 was between 22 and 41 years, thus excluding individuals that during the subsequent 23 years grew older than the conventional working age. Appendix A.3 describes the selection procedure in a deeper detail. As in the reference literature, non-employment spells are treated as periods with zero days worked and zero earnings. ${ }^{29}$. Days worked and gross earnings are cumulated from 1994 to 2016, tracking changes in employer (see Appendix A.3) The dependent variable for cumulated gross earnings is defined as the ratio of the cumulated real gross earnings from 1994 to 2016 over the real gross earnings in 1993 (multiplied by 100); the dependent variable for wage is computed as $100 \times \log$ the ratio between the cumulated real gross earnings and the cumulated days worked.

In the analysis of entrant shares, entrant workers are individuals with positive amounts of days worked and earnings in 1993 but no job spell during the previous three years since the first available year in the employee dataset is 1990. For consistency reasons, the same 3-years backward window is used to define entrants workers in 2016. Re-entrants are individuals who worked in 1993 (2016), had no job spell the year before but had at least one job spell with positive earnings during the previous two years. Appendix A.3 provides more details and describes how each (re)entrant worker is associated to a LLM91 using data on firm location from the matched employer-employee dataset. Given LLM-industry cells, the difference between 1993 and 2016 in the sectoral share of (re)entrants out of the total number of (re)entrants in the LLM91 is the dependent variable in Eq. (9) and measures the likelihood that a worker (re)enters into employment in each sector for each LLM.

\section{Descriptive evidence}

Italy is an interesting case to study the long-term effect of robots on employment. Since the early 1990s Italy has been steadily ranked second among European countries in terms of operational stock of robots (Figure 1a). ${ }^{30}$ Until about the onset of the financial crisis the growth rate of robot stock in Italy was similar to Germany; then it flattened and the gap with Germany increased (Figure $1 \mathrm{~b}$ ). A slowdown in the growth of robots in connection with the crisis was experienced also by other countries (e.g. Finland and France), while in countries like Denmark and Sweden the diffusion of robots continued growing intensely also in recent years.

As shown in Figure 2a, in Italy in 2016 the robot stock was more concentrated in industries such as 'automotive', 'metals', 'plastic and chemical products' and 'food and beverages'. The first two industries actually had a considerably higher share in 1993, while for the other two industires the share was much thinner then. Figure $2 b$ shows the dynamics over time: the automotive sector

\footnotetext{
${ }^{29}$ It is not possible to disentangle whether in those period the person was inactive, unemployed or self-employed.

${ }^{30}$ This holds both in absolute and per capita terms. The higher level of robot per worker measured for Spain with respect to Italy after the crisis is mainly driven by the relevant fall in Spanish employment.
} 
reached its peak and then stopped growing roughly in coincidence with the years when the pace of growth of the total robot stock slowed down (Figure 1b). A similar cyclical pattern is displayed by the 'plastic and chemical product' industry, while the 'metal' industry's share (whose level was comparable to the automotive's one both at the beginning and at the end of the interval) exhibited a rather steady growth. The increased use of robots in the 'food and beverages' industry appears as a relatively recent phenomenon.

The sectoral distribution of robots in Italy is related to structural aspects of the Italian economy. In this respect, it is interesting to compare Italy to Germany and the US, since this study follows empirical approaches previously applied to analyse those countries. As shown in Figure 3, both in Germany and the US robots are much more concentrated than in Italy in the automotive sector, which in 2016 covered more than a half of the total robot stock; in fact, the automotive shares were even higher in 2004 (the first year for which data at sectoral level are available for the US). In Italy more mature industries, such as metal, plastic and chemical sectors, still cover a large share; their share is lower in Germany, and even thinner in the US. The plastic and of the chemical sector's share was originally higher in Germany than in Italy, but in Germany it did not expand further. In the US a considerable and growing share refers to the electronic industry.

These figures are informative about industries where robots are more concentrated, but they are less insightful about the intensity in the use of robots, i.e. how many robots are present per worker. In order to shed light on that, it is possible to divide the robot stock by the amount of (thousand) workers employed in the industry, using employment data from EU KLEMS (Fig. 4). Since the sectoral classes in EU KLEMS do not coincide with the IFR ones, some classes in each data source are joint in order to have a mutually consistent classification. ${ }^{31}$ As shown by the different scale of the two panels, the robot intensity is much higher in the 'automotive and other vehicle' class (Fig. 4a) than in the other sectors (Fig. 4b), while it remains substantially negligible in the textile industry. In general, the Italian sectoral robot intensities seem closer to those in Germany than in the US. ${ }^{32}$ There are however some differences with respect to Germany: for example, in the highly robot-intensive 'automotive and other vehicle' class, the intensity level was initially comparable, but then Italy lagged behind Germany, where the intensity considerably grew; in the plastic and chemical sector, in Italy the intensity growth was mainly concentrated in the first decade and slowed down afterwards, while in Germany the growth was steadier. As can be seen in Fig. $4 \mathrm{~b}$, in the US the robot intensity has particularly grown in the electronic industry, an industry more likely connected with several innovative applications, specially in the service sector. In Italy an industry with a remarkable growth is the 'food and beverages' one.

Focusing on Italy and moving back to the long-term perspective of the analysis, we can observe that at national level a slightly negative correlation emerges between the sectoral growth of robot stocks between 1993 and 2016 (normalized by the number of workers in each sector in

\footnotetext{
${ }^{31}$ This implies that, for instance, the IFR 'automotive' and 'other vehicle' sectors are grouped together. The weight of the 'other vehicle' sector was higher in Italy than in Germany and the US, especially in the initial part of the considered period.

${ }^{32}$ The US data by industry should anyway be considered with caution because, especially at initial years of data availability, a large part (e.g.: about $89 \%$ of the robot stock in 2004) was originally unclassified and so it has been assigned across sectors using shares of the classified stock, as explained is Section 3 and done also by Acemoglu and Restrepo (2017).
} 
1991) and the sectoral growth in employment (Figure 5). For an additional robot every 1000 workers, employment in the sector decreased on average by nearly 0.5 per cent between 1991 and 2016 (Fig. 5a). The automotive industry, the plastic and chemical products industry, and the food and beverages industry seem to drive the negative correlation according to their different degree of robot penetration. For several sectors that experienced a very different employment growth (from the declining textiles industry to the rising education and research sector) the incidence of robots barely changed, suggesting that other factors have affected the employment dynamics in the period. The negative relationship is stronger if the fitting line is weighted by initial employment in the sector (Fig. 5b).

In the estimation strategy, the instruments for robot exposure in Italy are based on the robot stock growth in other advanced European economies. Figure 6a shows the positive correlation at the sectoral level between the robot penetration in Italy and the analogous measure constructed by averaging robot data for other countries at the sectoral level. The automotive industry stands out among other sectors and could be driving the correlation. However, as can be seen in Fig. 6b, the positive correlation between the Italian pattern and the other countries' average is confirmed also when the relationship is fitted after excluding the automotive industry. Hence, at least in aggregate, the sectoral robot diffusion in other countries looks like a plausible predictor of the sectoral robot diffusion in Italy.

Moving to the LLM level, Figure 7a shows the intensity of the robot exposure in the 784 LLMs according to deciles of the distribution of $\Delta \mathrm{rob}_{r}^{I T}$. Northern Italy was on average more exposed than Central and Southern Italy, as confirmed by the descriptive statistics by macroarea reported in Table 2. However, the overall picture is not so clear-cut from a geographical point of view as there are quite exposed LLMs also in the South. In Figure $7 \mathrm{~b}$ an analogous map is presented for the predicted values based on a simple regression of $\Delta r_{r} b_{r}^{I T}$ on (a constant) and its instruments. By comparing the two maps, a high correlation can be detected but it is also clear that they do not perfectly overlap. Table 3 shows the 30 LLMs with the highest robot exposure. At the top four positions, there are in fact LLMs in Central and Southern in Italy, where important automotive plants were located: Termini Imerese, Cassino, Lanciano, Termoli. ${ }^{33}$

As explained in Section 2.1, two major macroeconomic shocks that characterized the period under analysis are controlled for: the increased trade with China and Estern Europe and the ICT technlogy diffusion. The intensity of exposure to trade with China and Eastern Europe is generally higher in the Northern and Central part of the country. ${ }^{34}$ Though this geographical pattern is roughly similar to the robot exposure's one, it does not systematically overlaps. Indeed, the correlation between net trade and robot exposure is significant (it is measured with a negative sign, at -0.38 , since exposure to trade is negative whenever imports exceed exports). If on the one hand this highlights the importance of including exposure to trade as a control, on the other hand it

\footnotetext{
${ }^{33}$ The Termini Imerese plant shut down in 2011. The Melfi LLM in Basilicata does not appear in this list as the plant was built between 1991 and 1993, while the exposure variable is based on employment shares in the Census year 1991.

${ }^{34}$ The map is not reported for the sake of space but available upon request. The ten most exposed LLM result Fabriano (Marche), Ivrea (Piedmont), Airola (Campania), Termini Imerese (Sicily), Comunanza (Marche), Sesto Calende (Lombardy), L'Aquila (Abruzzo), Sassoferrato (Marche), Conegliano (Veneto), Sessa Aurunca (Campania). Some of these LLM were specialized in household appliances and white goods productions, sectors with important import growth and production off-shoring.
} 
reassures on the possibility to identify a specific effect of robot exposure. Similar considerations hold by looking at predicted values obtained from regressions on exposures for the other countries: the correlation between predicted exposure to robot and trade scores at -0.40 . As far as ICT is concerned, as shown for Germany by Dauth et al. (2018), ICT equipment grew more in services than in manufacturing. ${ }^{35}$ This hints at a negative relationship between ICT exposure and robot exposure, as the latter tends to be higher in manufacturing. This is indeed what is found, with a negative correlation of -0.21 , statistically significant; the correlation is still significant and negative if predicted values were used (-0.15).

\section{Results}

\subsection{LLM analysis}

\subsubsection{Support to the identification strategy}

Summary statistics for LLM variables in model (1) are reported in Table 4 . The average manufacturing employment share in 1991 was 31\%; the exposure to trade with China and Eastern European countries has a negative sign on average as it is measured as export minus import. Before going to the main results, the analysis of first-stage regressions and some evidence of no pre-trend effects are presented to support the empirical strategy.

The first-stage regressions show that the endogenous variable exposure to robots is significantly correlated with its instruments, whether they are taken one by one or jointly (Table 5). The $R^{2}$ square ranges from 0.372 in the case of Norway to 0.756 in the case of Finland, where - as seen in Section 4 and Figure 1 - the pace of robot diffusion slowed down with the crisis and the great recession similarly to Italy. Interestingly, the $R^{2}$ in the regression with the Germany-based instrument is somehow in between these values: this is to some extent comforting as a priori one could suspect that the close commercial relationship between Italy and Germany could imply links in their use of robots, with possible endogeneity concerns if, say, Italian workers in some specific LLMs were employed to produce complementary or substitutive goods for German firms using robots. When all the countries are jointly taken, the Germany coefficient is not significant, while significance is found only for three countries (Denmark, UK and France), likely due to the high cross country correlations. Table 6 shows in panel (a) a similar analysis also for trade and ICT, whereas in panel (b) it reports the first stage regressions adding the covariates used in model (1). Instruments are found to have predictive power and they are jointly highly significant; the F-statistics is above 10 in all models and particularly high for the robot regression. This reassures against possible weakness of instruments.

Results for the pre-trend analysis are shown in Table 7. It is tested whether the robot exposure is correlated with pre-dated outcomes measured between 1981 and 1991, where outcomes

\footnotetext{
${ }^{35}$ The growth of gross fixed capital formation volume in sectors like Construction and Health and Social work (whose employment share is higher in the South than in the North) was higher than in sectors like transport equipment, electrical equipment, basic metal, and other manufacturing (which have higher employment shares in the North). These composition effects significantly contribute to higher average relative ICT exposure in the South. While it has to be taken into account that the accuracy of this measure of ICT exposure can be limited, ICT exposure is basically used as a control, refraining from any focus on its effect per se.
} 
are either employment growth (measured as log difference $\times 100)$ or change in $(100 \times)$ the employment to working age population ratio, considering first overall employment and then manufacturing and non-manufacturing employment separately. The model is estimated by 2SLS controlling for (instrumented) trade and ICT shocks, for area dummy and manufacturing share in 1981 (demographic variables in 1991 are not included as they would be endogenous in this regression). Both unweighted and weighted regressions are performed, the latter using employment in 1981 as weight. The results show that the exposure to robots in following years turns out to be never significantly correlated with previous trends of the dependent variable. This reassures against possible pre-trend effects.

\subsubsection{Results}

The main results from the baseline model are reported in Table 8. The first group of columns (1-6) refers to unweighted regressions. In column 1 controls include neither trade nor ICT exposure, then in column 2 the former is introduced and then in column 3 the latter is also added: the specification in column 3 represents the preferred one, similarly to Dauth et al. (2018). Exposure to robots turns out to be statistically non-significant in all specifications, with the smallest magnitude in the specification with full controls. The F-statistics in the preferred model is about 18, a value above the rule of thumb level of 10 under which instruments are usually considered weak. Note that the OLS coefficients (reported in the bottom rows) are positive and higher (though not significant), revealing a possible upward bias due to demand factors that may bring about co-movements between the use of robots and employment growth.

In columns 4-6, the estimates in the first three columns are replicated but saturating the model by means of more granular regional dummies instead of area dummies. This change however does not qualitatively impact the results that still suggest an effect statistically not different from zero. In columns 7-12 the described estimates are replicated by weighting observations by the initial employment. The weighted regressions are on the one hand informative to gauge the impact on total national employment, but on the other hand they are more sensitive to few big LLMs. In these regressions the effect of exposure to robots appears more negative, but remains statistically non-significant. When area fixed effects are replaced by regional fixed effects (columns 10-12), coefficients remain non-significant and get smaller in absolute values.

Then, manufacturing (panel A) and other sectors (panel B) are distinguished in Table 9. In panel A, the coefficients have negative sign and are higher in absolute value than for total employment, however their statistical significance is weak or absent. In particular, in the unweighted models (coulmns 1-6) a weak significance emerges only when trade and ICT shocks are not jointly controlled for; after including both these covariates as in the preferred specification (col. 3), the coefficient scores at -2.2 , but it is no longer significant at conventional levels. When regional fixed effects are added, the coefficient gets lower in magnitude and is not significant. In the weighted regressions, when considering the baseline specification with all controls and area fixed effects (column 9), the coefficient is weakly significant and similar in magnitude to the unweighted regression; again this effect gets smaller and lacks significance if area dummies are replaced by regional dummies. In all regressions the OLS coefficients are confirmed to be associated with a suspected 
upward bias. While noticing that the statistical evidence of a negative effect on manufacturing is at most weak, one can nonetheless try to assess its economic size by comparing the actual variation on average manufacturing employment to that predicted by the average robot exposure. According to this back-of-envelope computation, robot exposure could account for about one sixth (17\%) of the decline in manufacturing employment in the 25 years interval, a non-negligible amount, but somewhat lower than the $23 \%$ estimated by Dauth et al. (2018) in a similar exercise for Germany over a 20 years interval. Panel B of Table 9 report results for employment growth in non-manufacturing sectors: in this case, all models point to a clearly non-significant effect of robot exposure.

Table 10 summarizes the results obtained when considering as dependent variable the change in the employment to working age population ratio. ${ }^{36}$ Panel A and B refer, respectively, to unweighted and weighted regressions. Again, results are presented for overall employment (col. 1-3), manufacturing employment (col. 4-6), and non-manufacturing employment (col. 7-9). In each of these groups of columns, regressions are performed initially without trade and ict exposure, then with only trade, and eventually with both controls. The effect of robot exposure turns out to be significant in none of the specifications.

The results are robust if a different set of instruments is considered. The baseline model is based on an over-identified 2SLS regression using information on sectoral stocks of robots in other eight countries. The exclusion restriction requires that robot installations there have no direct impact on Italian LLMs. Worries may arise that this assumption is less likely to hold for countries to which Italy is more connected, such as those belonging to the Euro-Area. Therefore, following Dauth et al. (2018), estimates are replicated by considering only instruments based on countries external to the Area. In doing so, it is also tested that the null hypothesis of valid over identifying restrictions for robot instruments is not rejected at conventional statistical levels. Moreover, also just-identified estimates are performed by considering countries either one by one or their simple average. The results shown in Table 11 confirm the baseline findings of no substantial effect on overall employment and on non-manufacturing employment, while the coefficient on manufacturing employment is confirmed to be negative but generally not statistically significant. At the same time, this robustness check supports the use of multiple countries in the baseline specification as the F-statistics is sometimes low in the exactly identified regressions.

Results are also robust if a shorter time interval ending in 2011 is considered. Table 20 in Appendix B reports in Panel A the results of the baseline specification for both employment outcomes. ${ }^{37}$ Appendix $\mathrm{B}$ also reports the results of a heterogeneity analysis according to the initial situation with respect to robot intensity and employment share in tradable sectors. ${ }^{38}$ As shown in Table 21, the findings of no harmful impact on overall employment are confirmed for both groups; the statistically borderline-significant negative effect for manufacturing found in the baseline model is indeed concentrated in the LLMs where robots were more relevant; however, in these LLMs there is also a more beneficial effect on non-manufacturing employment (see Appendix B).

\footnotetext{
${ }^{36}$ Results are qualitatively substantially unaffected if whole population is used instead of working age population at the denominator of the ratio. These results are not reported for the sake of space but are available upon request.

${ }^{37}$ An even shorter span ending in 2001 was considered; however, in this case the interval for robot data is just eight years (1993-2001), thus being likely too short to assess a long run impact (see Appendix B).

${ }^{38}$ For each dimension, LLMs are split in two classes according to whether the initial situation was above or below the median; see Appendix B for details.
} 


\subsection{Incumbent workers analysis}

\subsubsection{Baseline results}

By estimating model (8), it is assessed if workers initially employed in sectors more exposed to robots actually ended up working more, less or substantially the same as workers employed in less exposed manufacturing sectors did. Given the individual level of the analysis, it is possible to net out for a number of confounding factors related to workers, employers and labour markets characteristics. Moreover it is possible to investigate whether individuals' careers involved changing firms, industry or sectors.

A summary of statistics for the sample of incumbent workers in manufacturing are reported in Table 12. In the sample, about one third of workers are female, while slightly more than $70 \%$ are occupied as blue-collars. ${ }^{39}$ About $6 \%$ of the incumbent workers in the sample were born abroad, about $70 \%$ work for firms in Northern Italy and the average age is about 31 years. In the last two columns of Table 12 one can see how means differ between two subgroups of workers defined according to whether they work in an industry with robot exposure above or below the median. Firms with higher robot exposure used to employ relatively more male workers, were on average larger and more frequently located in Northern Italy. This highlights the importance of controlling for worker, firm and area characteristics.

In Table 13 summary statistics are reported for the outcome variables (which are computed over the period from 1994 to 2016). Disentangling these outcomes according to whether they were associated to changes in firm / industry / sector, about $46 \%$ of total days worked and $39 \%$ of total earnings come from the original firm. The lower incidence for total earnings mirrors that the average wage obtained from the original firm is below the mean, while a value above the mean emerges for those who move to other firms within the same industry. Leaving manufacturing for other sectors (typically, services) is on average associated to the lowest wages. ${ }^{40}$

The 2SLS results from the estimation of model (8) are reported in Table 14. In Panel (A) the dependent variable is the number of cumulated days worked; in Panel (B) it is the cumulated real earnings indexed to real earnings in the base year (and multiplied by 100); in Panel (C) it is the log of the average wage (multiplied by 100) where this average is given by the ratio of cumulated earnings over cumulated days worked. In column (a) it is controlled only for trade and ICT exposure, instrumented as described above; in column (b) controls include those related to worker's characteristics; in columns (c) firm characteristics are added, while in column (d), which represents the favourite specification, controls at the local level are also included. ${ }^{41}$

The effect of robot exposure on days worked is positive and statistically significant. Once

\footnotetext{
${ }^{39}$ Both shares are neatly in line with those in Citino and Linarello (2019) based on the universe of Italian employee workers in manufacturing in 1991.

${ }^{40}$ This may reflect a number of factors that are outside the scope of this work, such as low valued added in many services where workers coming from manufacturing (mostly blue collar) happened to be employed, lower power of trade unions in the tertiary sectors compared to the secondary one, etc.

${ }^{41}$ Coefficients of control variables (not reported in Table 14) show that the amount of days worked is higher when the initial unemployment rate in the working province is low, employment rate is high, the firm size is bigger, the worker is born in Italy and is a male, is a white-collar rather than a blue-collar, has longer tenure, is aged between 31 and 35 years old, has higher initial earnings and a full-time contract. In all panels and columns the first-stage F statistic is high valued and statistically significant.
} 
worker and firm features are controlled for, the magnitude considerably diminishes but remains significant. After controlling also for regional dummies and labour market initial conditions the coefficient scores at 9.9. This implies that a worker at the $75^{\text {th }}$ percentile of the robot exposure distribution was employed for 93 days more than one at the $25^{\text {th }}$ percentile; the same difference taken between a worker at the $90^{\text {th }}$ percentile and one at the $10^{\text {th }}$ percentile extends to about 156 days. Considering that the time interval spreads over 23 years, the effect albeit statistically significant is not high from an economic point of view: 4.0 working days per year for the $75^{\text {th }}-25^{\text {th }}$ comparison (1.3\% of the 312 working days per year) and 6.8 working days per year for the $90^{\text {th }}-10^{\text {th }}$ comparison. These figures are slightly higher than those in Dauth et al. (2018), who also find a positive effect in Germany: 0.2 and 2.9 days per year in the two comparisons, respectively.

Panel B shows a statistically significant positive effect on cumulated earnings. It turns out that this is driven by the higher amount of days worked, while - as shown in Panel C - the effect on average wage is not significant. In this respect, results differ from Dauth et al. (2018), who finds a negative impact on wages driving a negative effect on cumulated earnings that offsets the positive one on days worked. ${ }^{42}$

\subsubsection{Results by employer}

In the next step of analysis, outcomes are distinguished according to whether the employee continued working for the same firm or changed employer. This helps highlighting which kind of career path drives the results shown above and whether the employment and wage resiliency is actually associated to mobility towards other firms and industries. In Table 15 the model specification with all controls (column 4 of Table 14) is maintained, while results for the three outcome variables (cumulated days worked, cumulated earnings and average wage) are shown in Panels A, B and C, respectively. In column (a) it is reported again the results found pooling all employers, while in the other columns outcomes are cumulated only if they are accrued: at the original firm (column b); in other firms but within the same manufacturing industry (column c); in firms belonging to other manufacturing industries (column d); in firms out of manufacturing (column e).

As shown in Panel A, the positive effect of robot exposure on total days worked is entirely due to employment at the same firm where workers were originally employed. The results in column (b) mean that workers employed in sectors with higher robot exposure continued working for the same firm longer than workers in less exposed sectors did. In other words, robot exposure has increased the duration of the employer-employee relationship. The impact is, however, not very large if we consider that it is referred to a span of 23 years: comparing workers at the $25^{\text {th }}$ and $75^{\text {th }}$ percentile of the robot exposure distribution, the increase in employment at the same firm amounts to about 8 working days per year and about 14 when comparing the $10^{\text {th }}$ and the $90^{\text {th }}$ percentiles.

\footnotetext{
${ }^{42}$ In a robustness check controls in model (8) inlcude also two classes of technology types according to the OECD classification of high versus low technology industries. The classification of technological content is based on OECD classification of NACE Rev. 2 codes - 2-digit levels. For manufacturing, two groups have been considered: one with low technological content (codes 10,11,12,13,14, 15, 16, 17, 18, 31,32) and those with at least medium level of technological content $(21,26,20,27,28,29,30,19,22,23,24,25,33)$. In an alternative robustness check controls include industries class dummies grouped in a similar way to Dauth et al. (2018): primary and food goods; consumer goods; industrial, capital and construction goods. Results are qualitatively in line with the baseline model and quantitatively show a mild attenuation of the effect of robots.
} 
This result can be compared to Dauth et al. (2018)'s: they also find a positive and significant effect on employment at the original firm and this effect - in comparison with both their overall effect and with the present estimates - is even stronger: conditional on remaining at the original firm, for the $90^{\text {th }}-10^{\text {th }}$ comparison they find an increase of 45 working days per year for more exposed workers.

At the same time, however, conditional on being separated from the original firm, workers coming from more exposed sectors generally happened to be employed for fewer days than workers coming from less exposed sectors. This negative effect is significant for workers that remained in the original industry or that left manufacturing (typically to work in the service sectors), while it is not significant for workers that relocate themselves to other manufacturing industries. However, even when significant, the effect can be quantified at most in less than 5 days per year in the $90^{\text {th }}-10^{\text {th }}$ percentiles comparison (less than 3 days in the interquartile comparison).

As shown in Panel (B), the higher amount of days worked at the same firm for workers in robot exposed sectors translates into higher cumulated earnings. For employees that continued working for their original employer, the difference in cumulated earnings between $90^{\text {th }}$ and $10^{\text {th }}$ percentiles corresponds to $7.7 \%$ of the average cumulated earnings ( $4.6 \%$ for the interquartile comparison). Conditional on leaving the original firm, the effect is negative if the individual remained in the same industry or moved out of manufacturing, but in the former case it is only weakly significant. Compared to its effect on days worked, the attenuation of the negative effect associated to changing firm within the same industry suggests a possible compensation through wages. This is indeed what is found in Panel (C), where the effect of robot exposure is shown to be positive for those who remained in the original industry, whether in the same firm or in others. The estimated coefficients represent semi-elasticities: using the formula $\exp \left(\hat{\beta_{1}} / 100-1\right) \times 100$, for workers remaining in the original firm this implies that a unit increase in exposure to robot per thousand workers increases wages by $0.11 \%$. Comparing workers at $90^{\text {th }}$ and $10^{\text {th }}$ percentiles of the robot exposure distribution the positive effect on wages at the original firm is $1.77 \%(1.05 \%$ the interquartile effect); evaluated at the base year average real daily wage and considering the average amount of days worked at the original firm, this implies almost 90 euros per year in the $90^{\text {th }}-10^{\text {th }}$ comparison and about 53 euros in the $75^{\text {th }}-25^{\text {th }}$ comparison.

All in all, this evidence suggests that incumbent workers have not lost on average from working in sectors more exposed to robots. Nevertheless, this holds on average and does not imply that there were not winners and losers, even if the amount of both winnings and losses does not seem very large. The winners appear to be workers that remained at the original firm, since they managed to be employed longer and paid more. It is possible that this indirectly reveals a selection on workers (not removed by control variables), as firms preferred to keep "better" workers and separate from "worse" workers. Anyway, should this be the channel, the results suggest that it has to be stronger in industries where robots are used more. A kind of trade-off seems to emerge for those that relocate themselves within the manufacturing industry, while those that left manufacturing to go to other sectors, mainly services, seem to be net losers, as they were employed less and eventually cumulated lower earnings.

A possible explanation is that in robot exposed industries firm-specific human capital and 
robots implementation were to some extent complementary, thus favoring a long-term relationship between the worker and the firm. Workers that moved to other firms in the same industry faced a trade-off between a period as unemployed and a higher wage. It is possible that they may gain from industry-specific human capital but they encounter friction costs before matching another employer in the industry. Another possible interpretation of these results - which however cannot be investigated in our framework since the measure of robot shock is at industry level would be consistent with findings from studies based on firm-level data (Koch et al., 2019; Acemoglu et al., 2020) that show a positive employment effect for firms that actually introduced robots and a negative effect for their competitors that did not. In this sense, the result of a positive effect conditional on remaining at the same firm would capture the effect of firms that actually invested in robots, while the negative effect of robot exposure conditional on leaving the original employer would be mostly related to firms that did not invest in robots.

\subsubsection{Heterogeneity}

The overall picture emerging from this analysis seems to suggest that robots could have been in some cases a complement and in others a substitute for labour. ${ }^{43}$ It thus seems interesting to explore workers' features according to which these effects may vary. In this respect, the following workers' characteristics are considered: gender, age class, initial earnings class, initial occupation class, and geographical area. Operationally, each variable is included in model (8) in level and in interaction with robot exposure; the interaction coefficient is informative of heterogeneous effects. Results are presented in Table 16.

The analysis by occupational classes shows that the employment effects are in general stronger for blue collars than for white collars, but white collars (and managers even more) benefit in terms of wages. In this sense, the diffusion of robots would not have hindered blue collars' employment but could have contributed to increasing wage differentials. It is also possible that, at least in part, these outcomes could reflect changes in bargaining power between workers and firms, where job stability for blue collars is traded with a lower participation to productivity gains.

With respect to gender, results point at a relatively more beneficial effect for women in terms of days worked, but this mostly occurs through employment in other sectors. This could suggest that women may have been re-employed in the service sectors sooner than men. However, this positive employment effect for women when leaving the original firm is not associated to higher earnings or wages.

The analysis by three age classes suggests that the eldest cohort benefited less from the employment enhancing effect of robot exposure at the original firm, while the youngest cohort had worse outcomes in terms of wages, especially outside the original firm. It is possible that in more robot-intensive sectors the productivity gains and the expected savings on labour costs could have encouraged firms to support early-retirement scheme. On the other hand, the availability of robots may have reduced the bargaining power of young workers, also by moving them towards less

\footnotetext{
${ }^{43}$ On complementarity and substitutability between human work and robots see DeCanio (2016) and Autor (2015). Autor and Salomons (2018) discuss how the relationship between automation and its impact on labour demand may have varied over time.
} 
unionized sectors.

Considering three classes of initial earnings, for less-paid workers there is a weak evidence of a positive employment effect on the one hand and a negative wage effect on the other hand. Both effects actually occur outside the original firm: it is possible that the low paid are also those that are separated more easily from their initial firm and moved to service sectors, where however they were likely employed in less paid occupations. Finally, perhaps surprisingly, the positive employment effect of robot exposure turns out to be higher for workers that were initially employed in Southern Italy. However, this does not occur at the original firm and it could be that after the separation with the original Southern firm workers moved to the North, where job opportunities are higher.

Dauth et al. (2018) also investigate mobility through occupations. In the present dataset only changes between macro-categories (such as collar types) can be explored. Considering only workers initially employed as blue collars, Table 17 shows that only $7 \%$ of their cumulated days worked and only $4 \%$ of days worked at the original firm are assoicated to a switch into a white collar occupation. This share achieves $15 \%$ when associated to a transition out of manufacturing. For blue collars that siwtched into a white collar occupation, the employment effect of robot exposure is negative, especially when associated to leaving the original firm. This may suggest that reconverting is not easy as it may involve time and friction costs.

\subsection{Entrant workers analysis}

The analysis in Section 5.2 is informative about the effects of robots for incumbent workers, but it does not provide any information on what happened to flows of new labour forces. To shed light on that, in this last part of the analysis worker-level data are combined with the LLM-level approach (similarly to Dauth et al., 2018). In particular, model (9) is estimated, where observations are sector-LLM cells, the dependent variable is the change in the sector share out of total entrant workers in each LLM, and the robot shock is given by the sectoral robot shock weighted by the pre-determined employment share of the sector in 1991 (see Section 2.3). Then, the same analysis is carried out for re-entrants workers, defined as described in Section 3. In all models, controls include the initial socio-demographic conditions and the initial share of manufacturing as in the LLM-level analysis. Observations are weighted by the LLM's employment share in each sector in 1991; also unweighted estimates are carried out to check how sensitive results are to few large LLMs.

As a descriptive evidence, Figure 8 shows that the sample average share of entrant workers in manufacturing sectors decreased from $24.1 \%$ to $16.2 \%$ between in 1993 and 2016. In the same period, the share of re-entrants workers employed by manufacturing sectors also narrowed (from $21.0 \%$ to $15.0 \%$ on average). This decreasing trend, however, does not per se imply that the fall was higher in LLMs more exposed to robots.

The results from the estimate of model (9) are reported in Table 18 and Table 19 for entrant workers and for re-entrant workers respectively. In the first three columns of each table macroarea dummy variables are used, whereas in the last three columns they are replaced by more granular regional dummy variables. Within each group of columns, the first one does include neither 
trade nor ICT shocks, the second one adds the control for trade shock only, while the third column includes the ICT shock too. The results are quite robust across specifications and they point at a negative effect of the robot exposure on the likelihood of entering the industry. Also the unweighted estimates (reported in the bottom part of the table) provide negative and significant results suggesting that large LLMs are not the drivers of these effects.

An indirect estimate of the size of the robot effect can be derived by summing over the manufacturing industries the predicted impact of the sector-weighted robot shock. This can be compared to the actual total decrease in the manufacturing share of entrant workers: according to this exercise and to estimates in column (c) of Table 18, the robot exposure is accountable for about one fifth of the observed decrease in the likelihood of entering manufacturing.

For re-entrant workers results are similar (Table 18). The robot exposure has a negative and significant effect that is robust across model specifications and is not driven by large LLMs. The magnitude of the effect is just slightly lower but not far from the size estimated for entrant workers. By repeating the same exercise described above, it can be estimated that robot shocks accounted for $21 \%$ of the overall decrease in the likelihood of re-entering in manufacturing, basically the same incidence found for entrant workers.

\section{Conclusive remarks}

Robotization represents one of the main challenges for the future of work. So far, however, the empirical evidence on the causal impact of robots on employment is not conclusive. Among studies taking a within-country perspective, displacement effects seem to prevail for the US, whilst for Germany a less pessimistic picture emerges, with no negative impact on overall employment. The present work contributes to this literature by studying the employment effect of increased robot diffusion in Italy since the early 1990s up to 2016. Italy is an interesting case to enrich the available evidence on the topic as throughout the whole period it has ranked as the second European country after Germany in terms of robot stocks. Moreover, as done by Dauth et al. (2018) for Germany, this work complements the analysis at the local labour market level with an individual level analysis, to investigate the impact on workers' careers and on the likelihood of entering into employment through robot exposed sectors.

In order to identify the effect of robot exposure, the applied instrumental variable strategy is based on sectoral diffusion of robots in other advanced European economies, with the aim of capturing common supply factors while purging from demand and other confounding factors. In addition, to reduce the risk of spurious correlation due to omitted variables, the empirical model has accounted for concurrent macro trends related to trade with Chinese and Eastern European markets and to the ICT diffusion, as well as controlling for the declining trend in manufacturing employment in favour of service sectors.

At the local labour market level, the results - which encompass indirect and general equilibrium effects - show that local employment was not negatively affected from being exposed to robots. If any, some weak evidence of a negative effect emerges for manufacturing employment only. Such an effect, however, does not seem to be due to a negative impact on incumbent work- 
ers: indeed the individual level analysis suggests that incumbent employees in manufacturing were not negatively affected on average by working in sectors more exposed to robots. This average result for incumbents actually hides different effects (positive for those who remained at the original firm, negative for those who relocated elsewhere out of manufacturing), but their size is generally not high considering the long-term interval over which the outcomes are cumulated. The adjustment to robots seems to have rather occurred through a lower likelihood of entering manufacturing for new workers: based on the estimates, it is possible to gauge that increased robot diffusion could account for about one fifth of the decline in the share of new workers entering manufacturing.

All this evidence suggests that the employment effect of the increased use of robots has mostly consisted in reshaping the demand for new labour forces and their allocation, but without detriment for the overall employment. Compared to previous similar studies, hence, the evidence emerging for Italy seems more in line with Germany and less pessimistic than in the US. This could be related to several characteristics with respect to which Italy seems closer to Germany than to the US. These include to the institutional setting and employment protection rights in the labour market, which are more rigid for incumbent (insiders) than for new entrants (outsiders); others are related to the production structure, with the relatively more important role of manufacturing and the relatively lower one of advanced services (as shown, this is mirrored in the sectoral distribution of robots).

These findings have several policy implications. For example, concerning the debate on robot taxation, they provide evidence against the hypothesis of a harmful effect of robots on employment, in addition to the available evidence of a positive effect of robots on productivity (Graetz and Michaels, 2018; Dinlersoz and Wolf, 2018). Moreover, the inspection of impacts on individual careers suggests that the effects (even for workers that are negatively affected) were on average not high and so they could be tackled by specific policy instruments to favour workers' reallocation, such as training or temporary subsidies. Similar policy implications can be derived from the reallocation effect from manufacturing to non-manufacturing that the local level analysis ha shown, in particular concerning changes in the sectoral distribution of new workers. In general, training and education policies could be aimed at investing in skills that highlight and enhance the complementarities between humans and robots, such as problem solving skills, adaptability, creativity (Autor, 2015), rather than on tasks that can be performed by robots as well.

At the same time, it is fair to say that any attempt to infer indications for the future based on past evidence is not without problems or warnings. As far as the institutional and technological background behind the analysis exhibits a degree of inertia, one could expect that these results could be informative also for the next future. However, in this respect, at least a couple of caveats are worth expressing. First, it has to be taken into account that the speed of diffusion of robots considerably decelerated in Italy with the great recession, but it could accelerate again as new and more flexible (and cheaper) robots spread out. Second, even if the pace of diffusion remains steady, the linearity of the effects cannot be taken for granted as innovations can have quite peculiar and unpredictable impacts. While lessons for future should be taken with caution, this research nonetheless suggests that so far in Italy robot diffusion has not been per se harmful for overall 
employment, nor it has brought about displacement of incumbent workers, for whom it has rather contributed to lengthening the job relationship with their firms.

\section{References}

Acemoglu, D. and Autor, D. (2011). Skills, Tasks and Technologies: Implications for Employment and Earnings. In O. Ashenfelter and D. Card (eds.), Handbook of Labor Economics, Handbook of Labor Economics, vol. 4, 12, Elsevier, pp. 1043-1171.

-, Lelarge, C. and Restrepo, P. (2020). Competing with Robots: Firm-Level Evidence from France. Working Paper 26738, National Bureau of Economic Research.

— and Restrepo, P. (2017). Robots and Jobs: Evidence from US Labor Markets. NBER Working Papers 23285, National Bureau of Economic Research, Inc.

— and - (2018). The Race between Man and Machine: Implications of Technology for Growth, Factor Shares, and Employment. American Economic Review, 108 (6), 1488-1542.

- and - (2019). Automation and new tasks: How technology displaces and reinstates labor. The Journal of Economic Perspectives, 33 (2), 3-30.

Aghion, P., Antonin, C., Bunel, S. and JARAVel, X. (2020). What Is the Impact of Automation on Employment? New Evidence from France. Tech. Rep. 14443.

Arntz, M., Gregory, T. and Zierahn, U. (2016). The Risk of Automation for Jobs in OECD Countries: A Comparative Analysis. OECD Social, Employment and Migration Working Papers 189, OECD Publishing.

AUTOR, D. (2014). Polanyi's Paradox and the Shape of Employment Growth. NBER Working Papers 20485, National Bureau of Economic Research, Inc.

— and SAlomons, A. (2018). Is Automation Labor Share-Displacing? Productivity Growth, Employment, and the Labor Share. Brookings Papers on Economic Activity, 49 (1), 1-87.

Autor, D. H. (2015). Why Are There Still So Many Jobs? The History and Future of Workplace Automation. Journal of Economic Perspectives, 29 (3), 3-30.

-, Dorn, D. and HAnson, G. H. (2013). The China Syndrome: Local Labor Market Effects of Import Competition in the United States. American Economic Review, 103 (6), 2121-2168.

- , - , - and SonG, J. (2014). Trade Adjustment: Worker-Level Evidence. The Quarterly Journal of Economics, 129 (4), 1799-1860.

BACKer, K. D., DeStefano, T., MenOn, C. and SuH, J. R. (2018). Industrial robotics and the global organisation of production. OECD Science, Technology and Industry Working Papers 2018/03, OECD Publishing. 
Barbieri, L., Mussida, C., Piva, M. and Vivarelli, M. (2019). Testing the Employment Impact of Automation, Robots and AI: A Survey and Some Methodological Issues. IZA Discussion Papers 12612, Institute of Labor Economics (IZA).

Bessen, J., Goos, M., Salomons, A. and VAn Den Berge, W. (2019). Automatic Reaction - What Happens to Workers at Firms that Automate? Tech. Rep. No. 19-2, Boston University School of Law, Law and Economics Research Paper.

-,,- - and - (2020). Automation: A guide for policymakers.

Bloom, N., Draca, M. and Van Reenen, J. (2016). Trade Induced Technical Change? The Impact of Chinese Imports on Innovation, IT and Productivity. The Review of Economic Studies, 83 (1), 87-117.

BONfiglioli, A., CRINÒ, R., FADINGER, H. and GANCIA, G. (2019). Robot imports and firm-level outcomes. QMUL.

BorJAs, G. J. and FreEMAN, R. B. (2019). From immigrants to robots: The changing locus of substitutes for workers. RSF: The Russell Sage Foundation Journal of the Social Sciences, 5, $22-42$.

CARbonero, F., ERnst, E. and Weber, E. (2018). Robots worldwide the impact of automation on employment and trade. ILO Working Papers 995008793402676 , International Labour Organization.

CARDI, O. and RESTOUT, R. (2015). Imperfect mobility of labor across sectors: a reappraisal of the Balassa Samuelson effect. Journal of International Economics, 97 (2), 249-265.

CHEN, W. and NABAR, M. (2018). The employment impact of automation following the global financial crisis: The case of industrial robot. In International Monetary Fund (IMF) (ed.), World Economic Outlook: Challenges to steady Growth, Ch. 2, Box 2.2, Washington, DC: IMF, Publication Services, pp. 90-92.

Chiacchio, F., Petropoulos, G. and Pichler, D. (2018). The impact of industrial robots on EU employment and wages: A local labour market approach. Working Papers 25186, Bruegel.

Citino, L. and LinARELlO, A. (2019). The impact of chinese import competition on italian manufacturing, working paper.

Coppola, G. and MazzottA, F. (2005). I sistemi locali del Lavoro in Italia: Aspetti teorici ed empirici. MPRA Paper 13173, University Library of Munich, Germany.

Dauth, W., Findeisen, S., Suedekum, J. and Woessner, N. (2018). Adjusting to Robots: WorkerLevel Evidence. Opportunity and Inclusive Growth Institute Working Papers 13, Federal Reserve Bank of Minneapolis.

DECANIO, S. J. (2016). Robots and humans - complements or substitutes? Journal of Macroeconomics, 49 (C), 280-291. 
Dinlersoz, E. and Wolf, Z. (2018). Automation, Labor Share, and Productivity: Plant-Level Evidence from U.S. Manufacturing. Working Papers 18-39, Center for Economic Studies, U.S. Census Bureau.

DixON, J., HONG, B. and WU, L. (2019). The employment consequences of robots: Firm-level evidence. Mimeo. Available at SSRN: https://ssrn.com/abstract=3422581 or http:/ /dx.doi.org/10.2139/ssrn.3422581.

DOBBS, R., MANYIKA, J. and WOETZEL, J. (2015). The four global forces breaking all the trends. Tech. rep., McKinsey Global Institute.

Dosi, G., Piva, M., Virgillito, M. E. and Vivarelli, M. (2019). Embodied and Disembodied Technological Change: The Sectoral Patterns of Job-Creation and Job-Destruction. IZA Discussion Papers 12408, Institute of Labor Economics (IZA).

EUROPEAN COMMISSION (2017). Attitudes towards the impact of digitisation and automation on daily life. Eurobarometer Special Report 460, European Commission.

Frey, C. B. and Osborne, M. A. (2017). The future of employment: How susceptible are jobs to computerisation? Technological Forecasting and Social Change, 114 (C), 254-280.

Gentili, A., Compagnucci, F., Gallegati, M. and Valentini, E. (2020). Are machines stealing our jobs? Cambridge Journal of Regions, Economy and Society, rsz025.

Goos, M. and Manning, A. (2007). Lousy and Lovely Jobs: The Rising Polarization of Work in Britain. The Review of Economics and Statistics, 89 (1), 118-133.

-, - and SAlomons, A. (2014). Explaining Job Polarization: Routine-Biased Technological Change and Offshoring. American Economic Review, 104 (8), 2509-2526.

Graetz, G. and Michaels, G. (2018). Robots at Work. The Review of Economics and Statistics, 100 (5), 753-768.

IFR (2018). World Robotics Industrial Robots.

KEYNES, J. M. (1930). Economic possibilities for our grandchildren. In Essays in Persuasion, Palgrave Macmillan UK. Ed. 2010, pp. 321-332.

KIRSTEN, J. (2016). EU KLEMS Growth and Productivity Accounts. Description of Methodology and General Notes.

Klenert, D., FernandeZ-MACiAs, E. and AntON, J.-I. (2020). Do robots really destroy jobs? Evidence from Europe. JRC Working Papers on Labour, Education and Technology 2020-01, Joint Research Centre (Seville site).

Koch, M., MAnuylov, I. and Smolka, M. (2019). Robots and firms. CESifo Working Paper Series 7608, CESifo Group Munich. 
LeONTIEF, W. (1952). Machines and man. Scientific American, 187 (3), 150-164.

MGI, MCKinsey Global Institute (2017). A Future That Works: Automation, Employment, and Productivity. McKinsey Publishing, executive Summary.

MOKYR, J., ViCKERS, C. and ZiEBARTH, N. L. (2015). The history of technological anxiety and the future of economic growth: Is this time different? Journal of Economic Perspectives, 29 (3), 31-50.

OECD (2018). Job creation and local economic development 2018.

O'MAHONY, M. and TIMMER, M. P. (2009). Output, input and productivity measures at the industry level: The eu klems database*. The Economic Journal, 119 (538), F374-F403.

RAJ, M. and SEAMANS, R. (2019). Artificial intelligence, labor, productivity, and the need for firmlevel data. In The Economics of Artificial Intelligence: An Agenda, University of Chicago Press, pp. 553-565.

RICARDO, D. (1821). On machinery. In On the Principles of Political Economy and Taxation, 3rd Ed., Ch. 31, pressed by Batoche Books, 2001, pp. 282-291.

Stehrer, R., BYkova, A., JÄGer, K., Reiter, O. and SchWARZhappel, M. (2019). Industry level growth and productivity data with special focus on intangible assets. Tech. Rep. WIIW Statistical Report No. 8, Vienna Institute for International Economic Studies.

Wren, A. (2013). The Political Economy of the Service Transition. Oxford University Press. 


\section{Figures}

Figure 1: Robot operational stock

(a) Absolute amounts

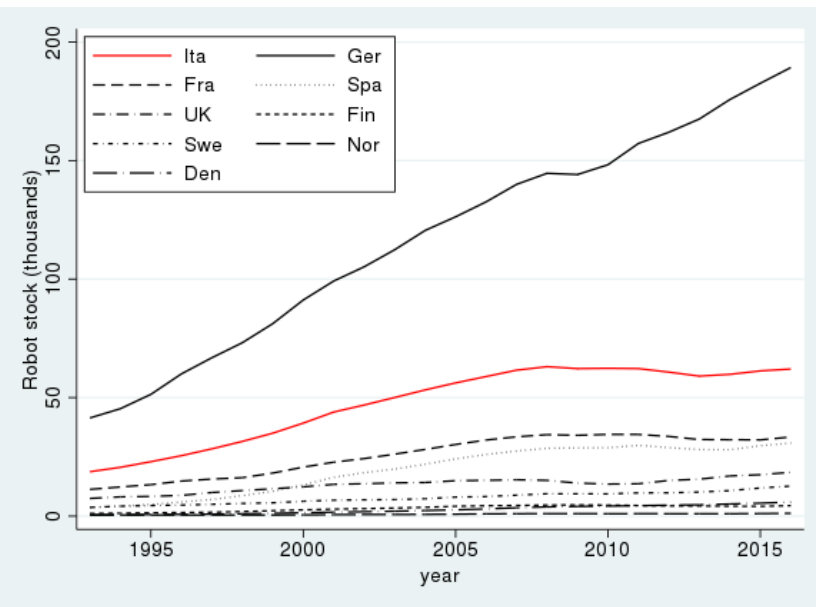

(b) Index: 1993=100

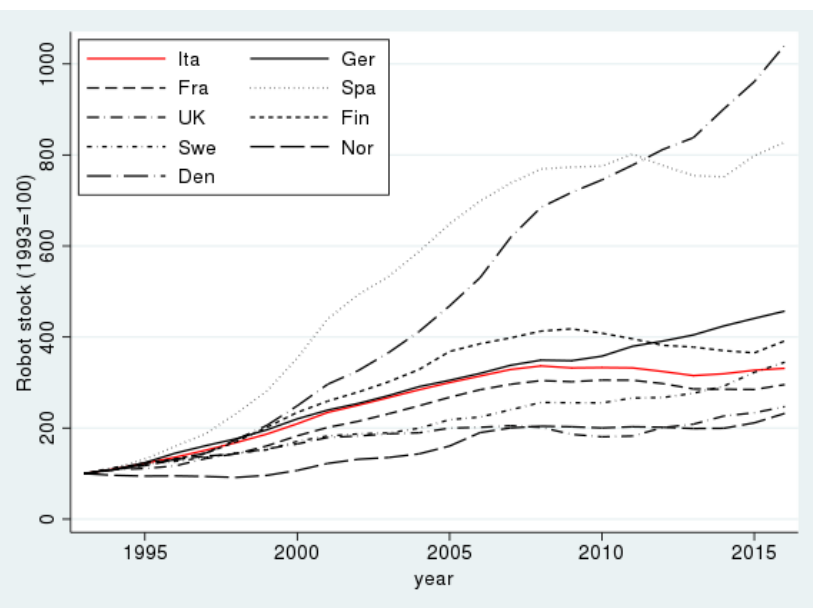

Source: our computations on IFR (2018) data.

Figure 2: Robot operational stock by sector in Italy

(a) Shares in 1993 and 2016 (per cent) (b) Over time (thousands)
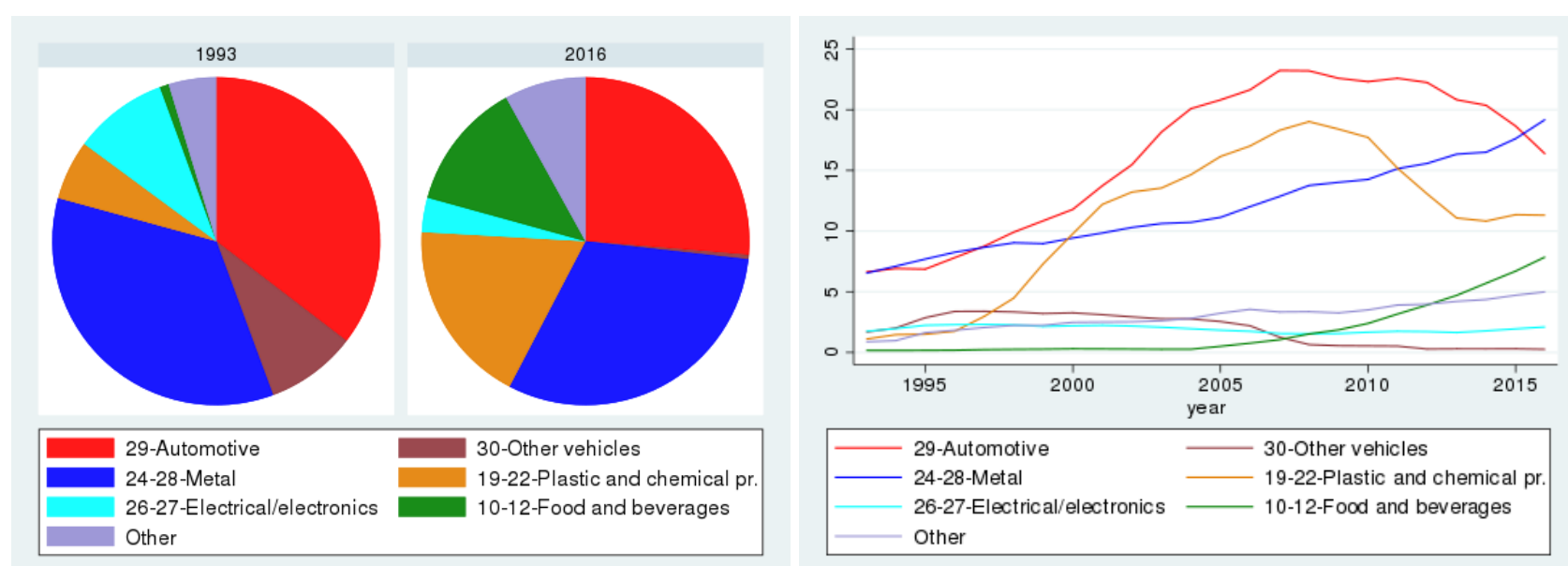

Source: our computations on IFR (2018) data. 
Figure 3: Sectoral distribution of robots in Italy, Germany and USA
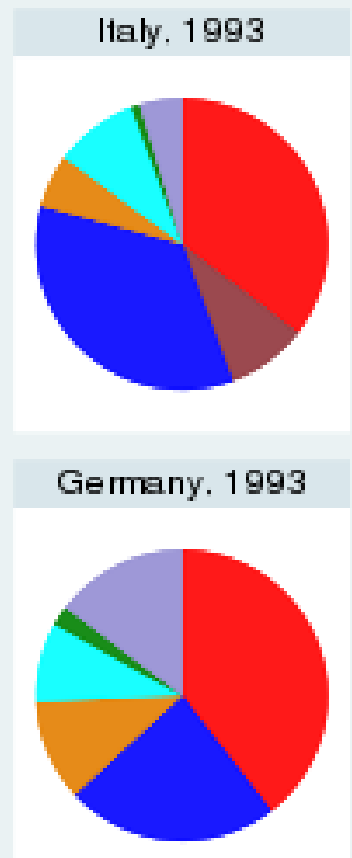

USA. 1993 |taly. 2004

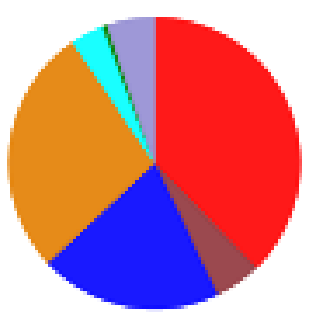

Gemany. 2004

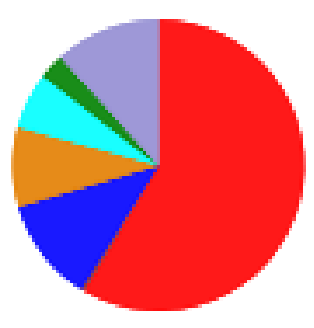

USA. 2004
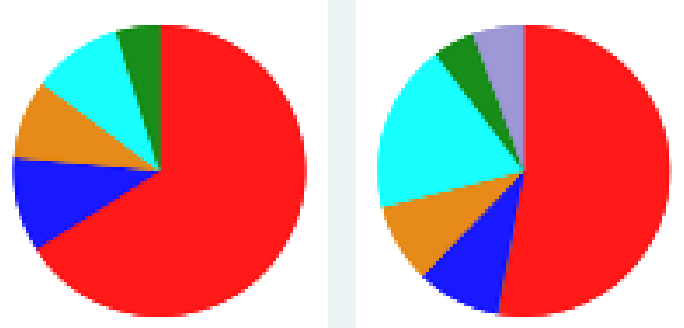

|laly. 2016

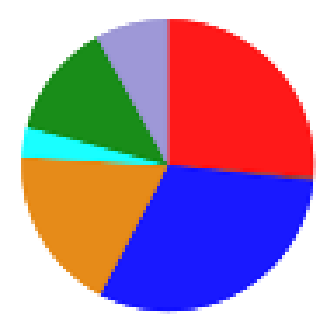

Gemany. 2016

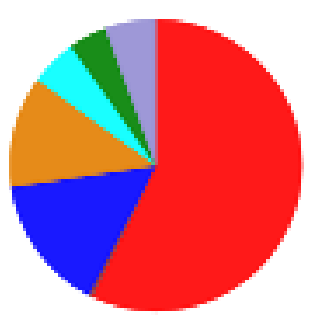

USA. 2016

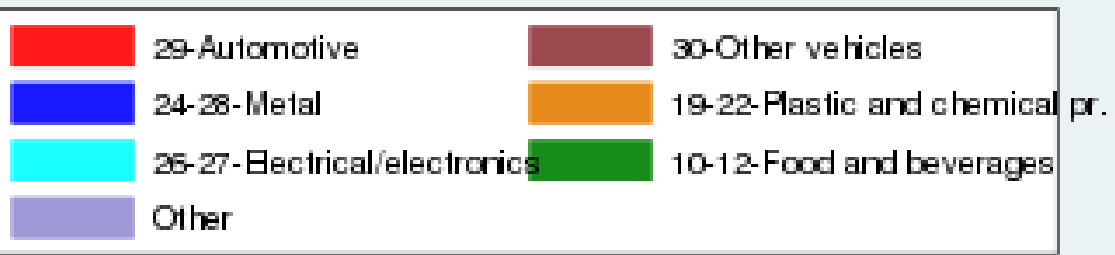

Source: our computations on IFR (2018) data. The sectoral distribution of robots in the US is not available before 2004. 
Figure 4: Robot intensity in Italy, Germany and USA

(robots per thousand workers)

(a) Automotive and other vehicles

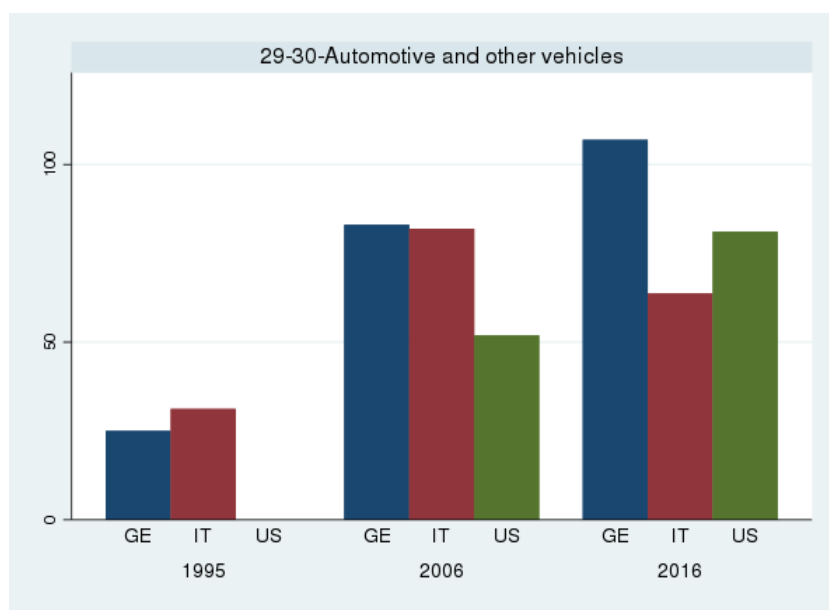

(b) Other sectors

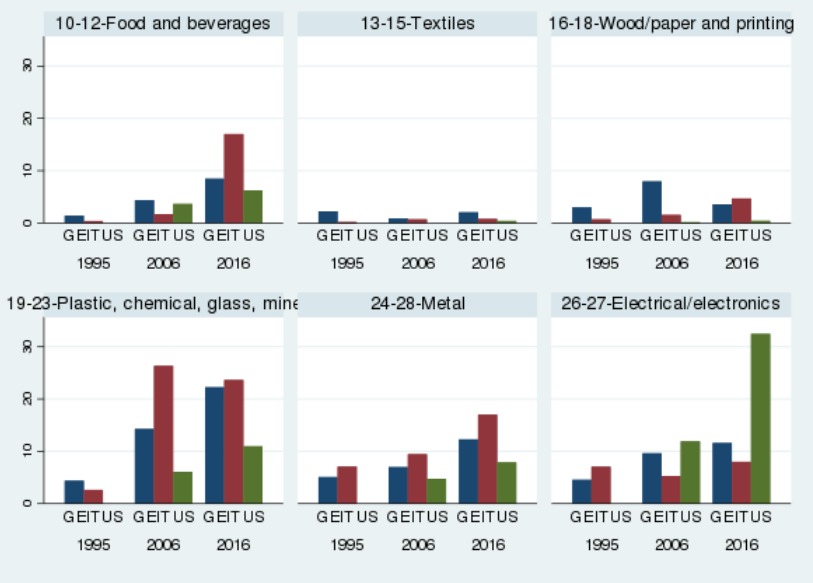

Source: our computations on IFR (2018) data for robots and EU KLEMS (Stehrer et al., 2019) data for employment. Data on the sectoral distribution of robots for the US are not available before 2004. Due to different classifications of sector groups between the two sources, sectors were further aggregated so to have consistent classes.

Figure 5: Employment growth and robot diffusion at the national level (1)

(a) Unweighted

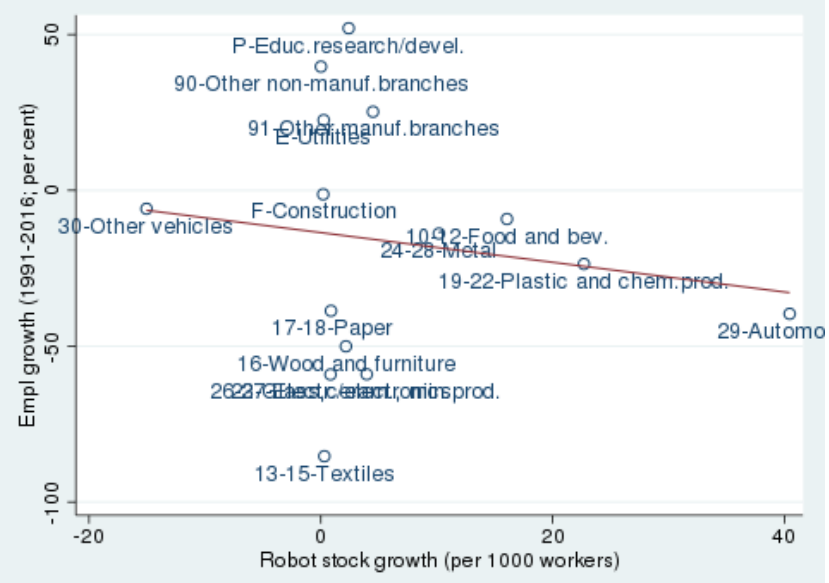

(b) Weigthed by 1991 employment

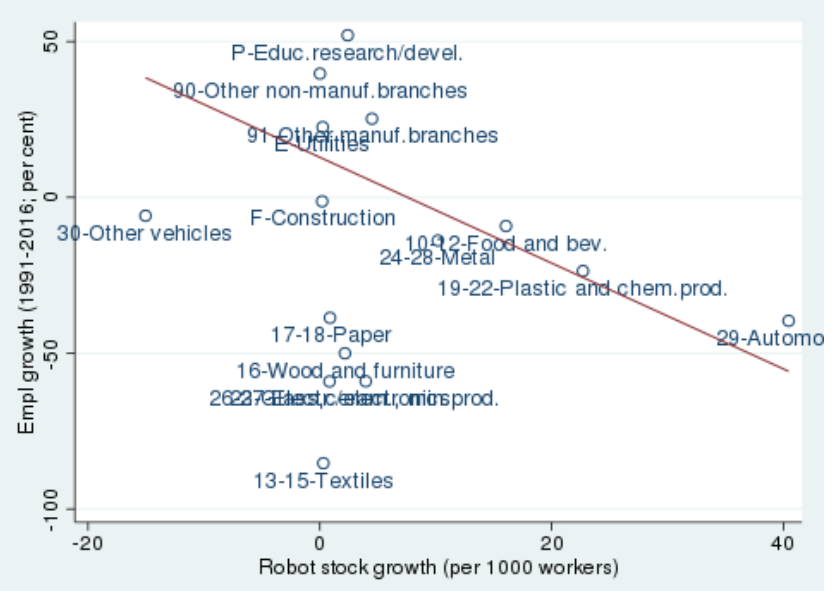

Source: our computations on IFR (2018) and ISTAT data.

(1) Employment growth between 1991 and 2016. Robot stock growth between 1993 and 2016 normalized by the number of workers in 1991. 
Figure 6: Robot stock growth by sector In Italy and other countries' average

(a) Inlcuding automotive

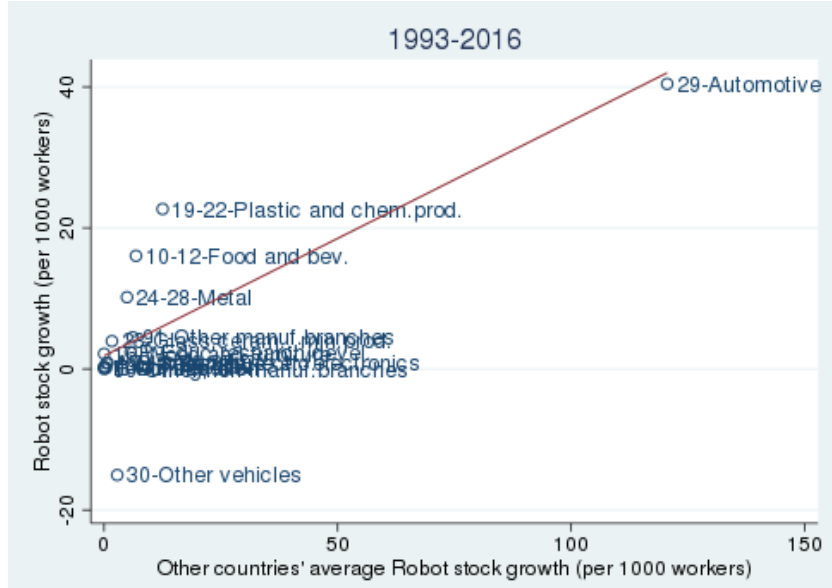

(b) Excluding automotive

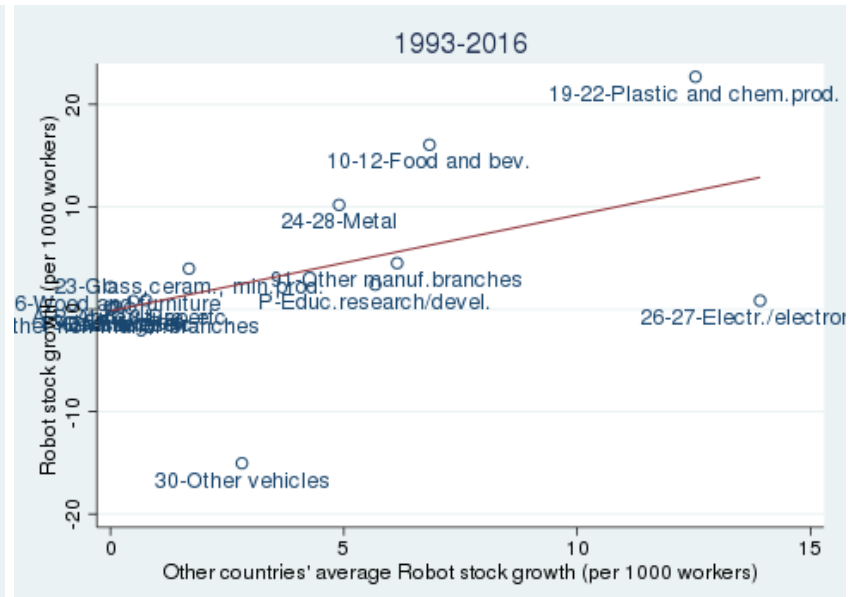

Source: our computations on IFR (2018) and ISTAT data.

Figure 7: Exposure to robots for Italian LLMs

(a) Actual

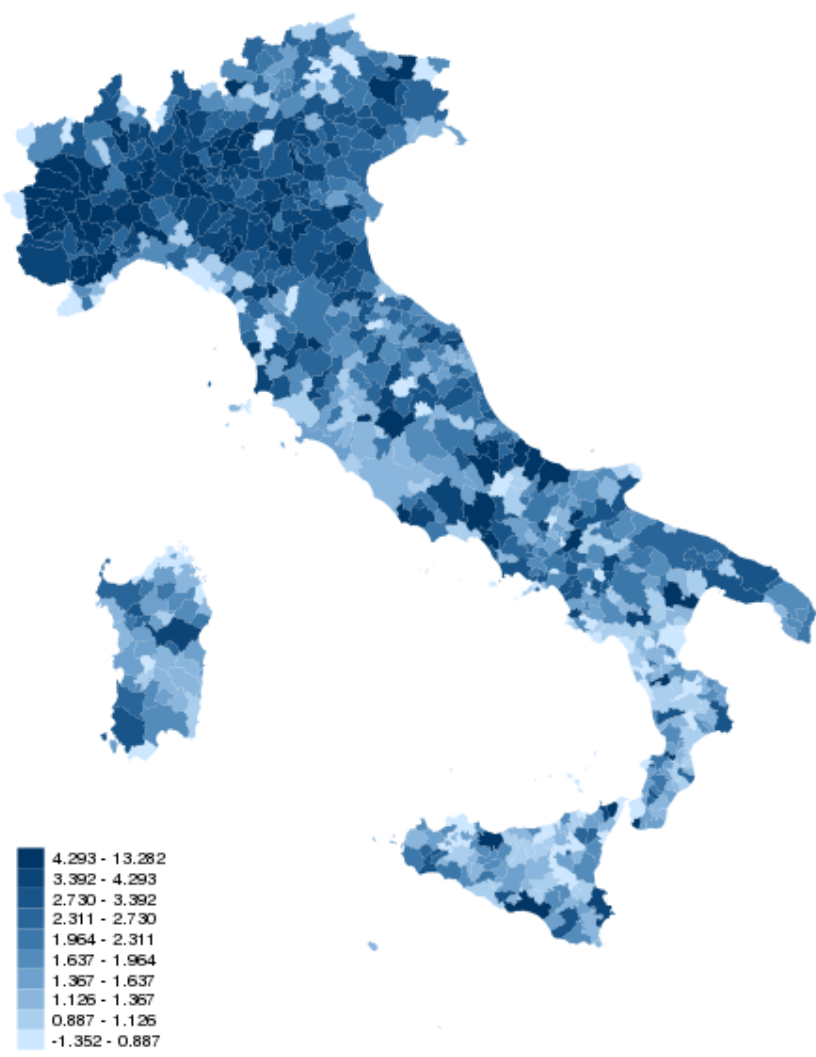

(b) Predicted

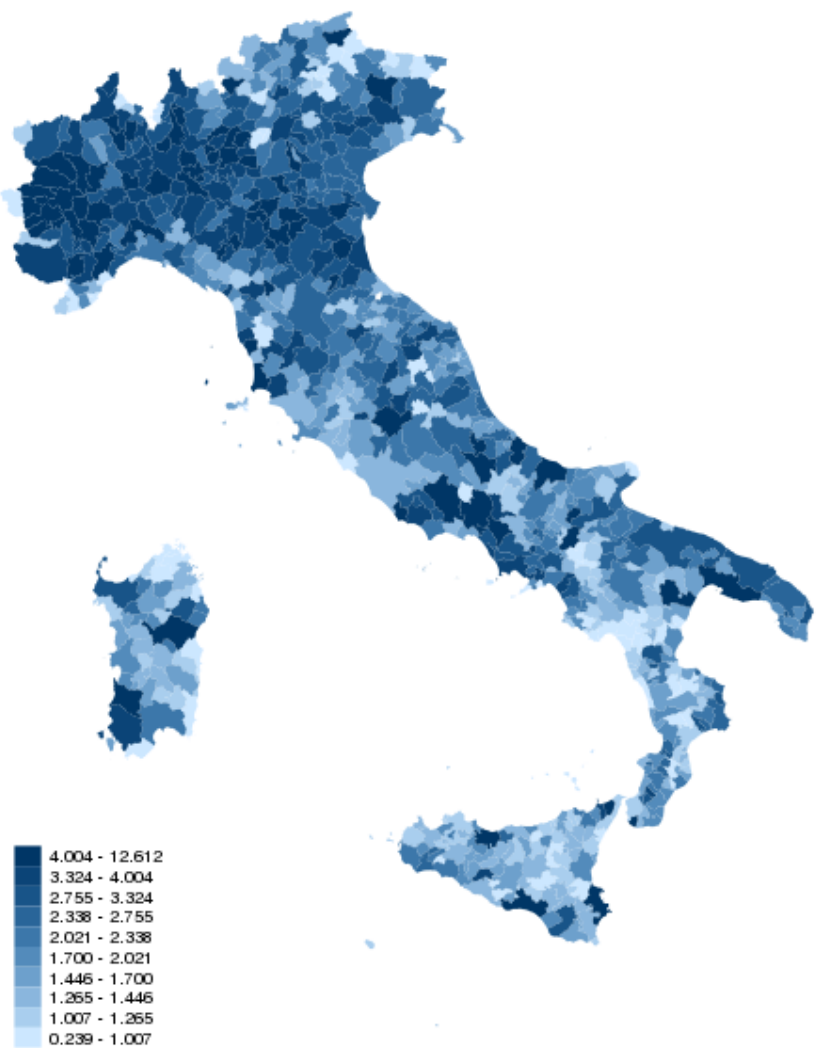

Note: LLM are defined according to 1991 borders. Panel (a): Classes are defined according to the distribution of $\Delta r o b_{r}^{I T}$, where the difference is taken up to 2016. $\Delta_{t} r o b_{r}^{I T}$ is computed as defined in Equation 2. Panel (b): instead of actual values of $\Delta r o b_{r}^{I T}$, the prediction from the regression of this variable on a constant and the vector of instruments $\Delta_{t} r o b_{r}^{C}$ is considered. 
Figure 8: Entrant and re-entrant workers in manufacturing as share of total entrant and re-entrant workers in the LLM

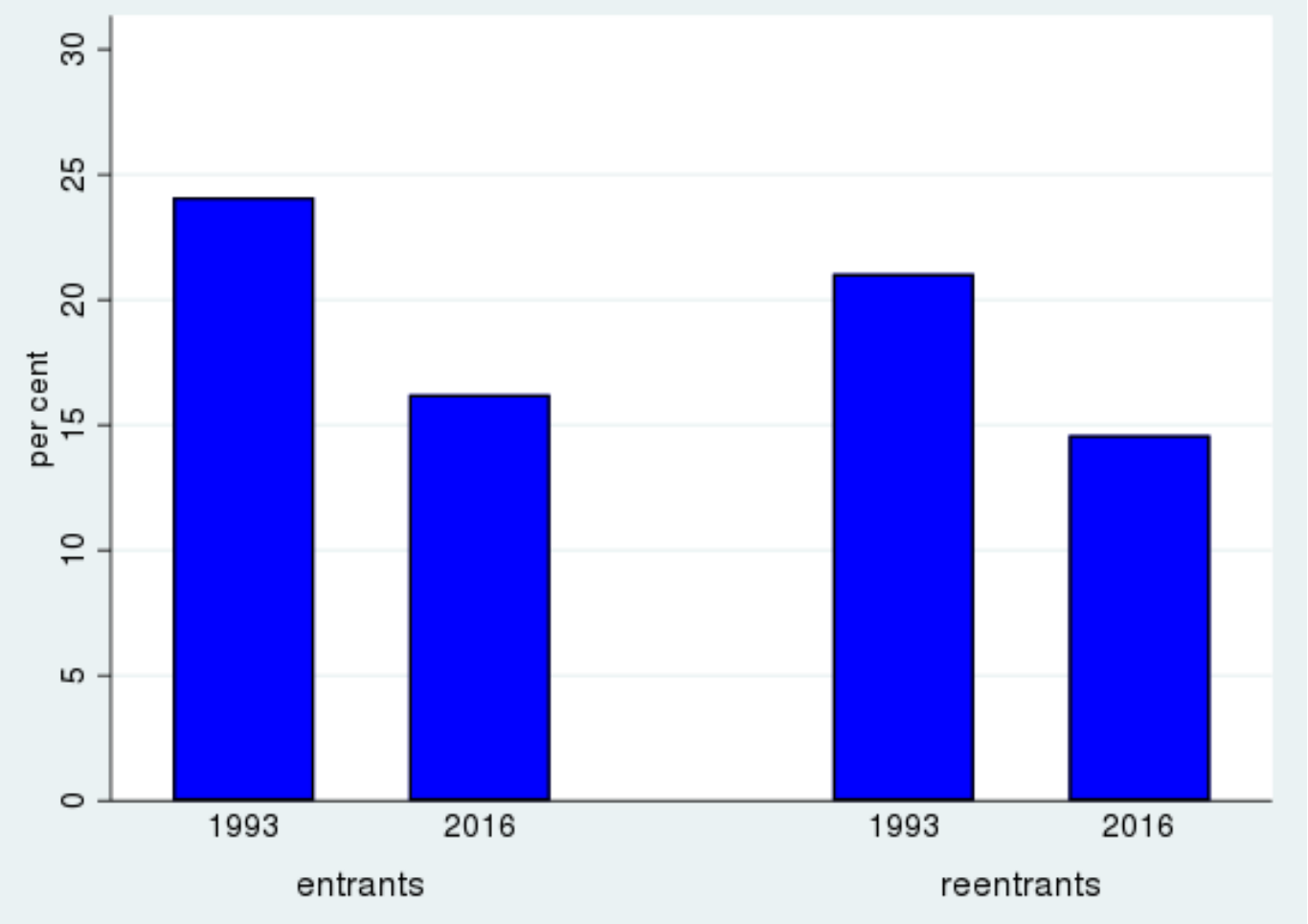

Notes: simple average of the entrants and rentrants workers (defined as described in Section 4) in manufacturing sector across LLM91s. 


\section{Tables}

Table 1: IFR sector groups

A-B-Agriculture, forestry, fishing (1)

C-Mining and quarrying (1)

10-12-Food and beverages

13-15-Textiles

16-Wood and furniture

17-18-Paper

19-22-Plastic and chemical products

23-Glass, ceramics, stone, mineral products (non-auto)

24-28-Metal

26-27-Electrical/electronics

29-Automotive

30-Other vehicles

91-All other manufacturing branches

E-Electricity, gas, water supply

F-Construction

P-Education/research/development

90-All other non-manufacturing branches

Source: Our computations on IFR (2018) data. Numbers correspond to 2 digit Nace Rev. 2 classification in manufacturing.

(1) Sector excluded from the analysis at the LLM because employment data for these sector are not available for 2016.

Table 2: Descriptive statistics of LLM exposure to robots by macroarea (1)

\begin{tabular}{lcccccc} 
macroarea & mean & sd & p25 & p50 & p75 & N \\
\hline North-West & 3.409 & 1.824 & 2.154 & 3.401 & 4.543 & 140 \\
Nord-East & 2.718 & 1.187 & 1.984 & 2.600 & 3.517 & 142 \\
Centre & 2.192 & 1.423 & 1.307 & 1.981 & 2.625 & 137 \\
South and Islands & 1.832 & 1.344 & 1.081 & 1.500 & 2.088 & 365 \\
Total & 2.337 & 1.546 & 1.250 & 1.964 & 3.055 & 784 \\
\hline
\end{tabular}

(1) Distribution of $\Delta_{t} r o b_{r}^{I T}$, where the difference is taken up to 2016. $\Delta_{t} r o b_{r}^{I T}$ is defined in Equation 2. 
Table 3: LLMs with the highest exposure to robots (1)

\begin{tabular}{lll} 
LLM & Region & Macroarea \\
\hline Termini Imerese & Sicily & South and Islands \\
Cassino & Lazio & Center \\
Lanciano & Abruzzo & South and Islands \\
Termoli & Molise & South and Islands \\
Barge & Piedmont & North-West \\
Torino & Piedmont & North-West \\
Cairo Montenotte & Liguria & North-West \\
Lumezzane & Lombardy & North-West \\
Carmagnola & Piedmont & North-West \\
Vestone & Lombardy & North-West \\
Ariano Irpino & Campania & South and Islands \\
Mondovi & Piedmont & North-West \\
Pisticci & Basilicata & South and Islands \\
Suzzara & Lombardy & North-West \\
Langhirano & Emilia-Romagna & North-East \\
Villar Perosa & Piedmont & North-West \\
Rivarolo Canavese & Piedmont & North-West \\
Avigliana & Piedmont & North-West \\
Chieri & Piedmont & North-West \\
Popoli & Abruzzo & South and Islands \\
\hline (1) The table reports the 30 LLM with the highest value of $\Delta_{t}$ robbr $b_{r}^{I T}$ where $\Delta_{t} r b_{r}^{I T}$ is \\
defined in Equation 2 and the ending year of the interval is 2016.
\end{tabular}

Table 4: Summary statics for the LLM-level analysis

\begin{tabular}{lrrrrr}
\multicolumn{1}{c}{ Variables } & Obs & Mean & Std. Dev. & \multicolumn{1}{c}{ Min } & \multicolumn{1}{c}{ Max } \\
\hline Female share & 784 & 0.511 & 0.008 & 0.477 & 0.547 \\
High school degree share & 784 & 0.168 & 0.039 & 0.065 & 0.299 \\
Graduated share & 784 & 0.027 & 0.012 & 0.005 & 0.083 \\
Over 50 years share & 784 & 0.346 & 0.059 & 0.201 & 0.589 \\
Foreign population & 784 & 0.005 & 0.004 & 0.000 & 0.038 \\
North-West & 784 & 0.179 & 0.383 & 0.000 & 1.000 \\
North-East & 784 & 0.181 & 0.385 & 0.000 & 1.000 \\
Center & 784 & 0.175 & 0.380 & 0.000 & 1.000 \\
South and Islands & 784 & 0.466 & 0.499 & 0.000 & 1.000 \\
Manufacturing share & 784 & 0.305 & 0.158 & 0.034 & 0.775 \\
Employment growth (1991-2016) & 784 & 6.800 & 22.464 & -78.909 & 102.478 \\
Change in emp./w.a. pop. (1991-2016) & 784 & 3.876 & 5.742 & -12.894 & 44.321 \\
Robot exposure & 784 & 2.337 & 1.546 & -1.352 & 13.282 \\
Trade exposure & 784 & -580.067 & 539.652 & $-4,707.877$ & 593.890 \\
ICT exposure & 784 & 0.215 & 0.075 & -0.060 & 0.581 \\
\hline
\end{tabular}

LLM are according to 1991 definition. Employment growth is measured as $(100 \times)$ log difference. All socio-demographic variables and the manufacturing share refer to 1991. Exposures, employment growth and changes in employment to working age population are computed for the time interval ending in 2016. 
Table 5: First stage regression of robot exposure on each and every instruments

\begin{tabular}{|c|c|c|c|c|c|c|c|c|c|}
\hline Country & $\begin{array}{l}(1) \\
\text { all }\end{array}$ & $\begin{array}{c}(2) \\
\text { Denmark }\end{array}$ & $\begin{array}{c}\text { (3) } \\
\text { Finland }\end{array}$ & $\begin{array}{c}(4) \\
\text { France }\end{array}$ & $\begin{array}{c}\text { (5) } \\
\text { Germany }\end{array}$ & $\begin{array}{c}(6) \\
\text { Norway }\end{array}$ & $\begin{array}{c}\text { (7) } \\
\text { Spain }\end{array}$ & $\begin{array}{c}(8) \\
\text { Sweden }\end{array}$ & $\begin{array}{l}(9) \\
\text { UK }\end{array}$ \\
\hline Denmark & $\begin{array}{c}7.090^{* * *} \\
(1.006)\end{array}$ & $\begin{array}{c}6.736^{* * *} \\
(0.206)\end{array}$ & & & & & & & \\
\hline Finland & $\begin{array}{l}-0.137 \\
(2.179)\end{array}$ & & $\begin{array}{c}12.36^{* * *} \\
(0.310)\end{array}$ & & & & & & \\
\hline France & $\begin{array}{c}-2.681^{* * *} \\
(0.849)\end{array}$ & & & $\begin{array}{l}1.181^{* * *} \\
(0.0896)\end{array}$ & & & & & \\
\hline Germany & $\begin{array}{c}0.0644 \\
(0.0422)\end{array}$ & & & & $\begin{array}{l}0.124^{* * *} \\
(0.0102)\end{array}$ & & & & \\
\hline Norway & $\begin{array}{c}4.684 \\
(5.765)\end{array}$ & & & & & $\begin{array}{c}41.19^{* * *} \\
(3.737)\end{array}$ & & & \\
\hline Spain & $\begin{array}{c}0.572 \\
(0.441)\end{array}$ & & & & & & $\begin{array}{l}0.825^{* * *} \\
(0.0674)\end{array}$ & & \\
\hline Sweden & $\begin{array}{c}0.662 \\
(0.742)\end{array}$ & & & & & & & $\begin{array}{c}3.345^{* * *} \\
(0.190)\end{array}$ & \\
\hline UK & $\begin{array}{c}2.169^{* * *} \\
(0.614)\end{array}$ & & & & & & & & $\begin{array}{c}1.409^{* * *} \\
(0.114)\end{array}$ \\
\hline Obs & 784 & 784 & 784 & 784 & 784 & 784 & 784 & 784 & 784 \\
\hline R-quared & 0.798 & 0.560 & 0.756 & 0.580 & 0.506 & 0.372 & 0.547 & 0.679 & 0.464 \\
\hline
\end{tabular}


Table 6: First stage regression of Robot, Trade and ICT exposure on their instruments

\begin{tabular}{|c|c|c|c|}
\hline & Robot & Trade & Ict \\
\hline \multicolumn{4}{|c|}{ Panel A: no covariates } \\
\hline \multirow[t]{2}{*}{ Denmark } & $7.090^{* * *}$ & $-1.283^{* * *}$ & $0.0413^{* *}$ \\
\hline & $(1.006)$ & $(0.223)$ & $(0.0204)$ \\
\hline \multirow[t]{2}{*}{ Finland } & -0.137 & -0.00689 & $1.110^{*}$ \\
\hline & $(2.179)$ & $(0.221)$ & $(0.590)$ \\
\hline \multirow[t]{2}{*}{ France } & $-2.681^{* * *}$ & $0.446^{* * *}$ & 0.0463 \\
\hline & $(0.849)$ & $(0.0715)$ & $(0.0622)$ \\
\hline \multirow[t]{2}{*}{ Germany } & 0.0644 & $-0.0453^{* *}$ & 0.0200 \\
\hline & $(0.0422)$ & $(0.0181)$ & $(0.0350)$ \\
\hline \multirow[t]{2}{*}{ Norway } & 4.684 & $3.570^{* * *}$ & \\
\hline & $(5.765)$ & $(0.349)$ & \\
\hline \multirow[t]{2}{*}{ Spain } & 0.572 & $-0.731^{* * *}$ & $0.211^{* * *}$ \\
\hline & $(0.441)$ & $(0.258)$ & $(0.0415)$ \\
\hline \multirow[t]{2}{*}{ Sweden } & 0.662 & $-0.809^{* *}$ & $-0.0272^{* * *}$ \\
\hline & $(0.742)$ & $(0.397)$ & $(0.00448)$ \\
\hline \multirow[t]{2}{*}{ UK } & $2.169^{* * *}$ & $-0.173^{* * *}$ & $0.109 *$ \\
\hline & $(0.614)$ & $(0.0391)$ & $(0.0576)$ \\
\hline Observations & 784 & 784 & 784 \\
\hline F-stat for all instruments jointly signif. & 358.4 & 68.9 & 89.2 \\
\hline R-squared & 0.798 & 0.494 & 0.552 \\
\hline \multicolumn{4}{|c|}{ Panel B: with baseline covariates } \\
\hline \multirow[t]{2}{*}{ Denmark } & $4.848^{* * *}$ & $-1.589^{* * *}$ & $0.0422^{* *}$ \\
\hline & $(0.930)$ & $(0.247)$ & $(0.0199)$ \\
\hline \multirow[t]{2}{*}{ Finland } & $3.436^{*}$ & $-1.381^{* * *}$ & $1.181^{* *}$ \\
\hline & -2.018 & $(0.348)$ & $(0.543)$ \\
\hline \multirow[t]{2}{*}{ France } & $-2.205^{* *}$ & 0.0654 & 0.0316 \\
\hline & $(0.908)$ & $(0.0940)$ & $(0.0501)$ \\
\hline \multirow[t]{2}{*}{ Germany } & $0.0988^{* *}$ & -0.00804 & -0.0199 \\
\hline & $(0.0434)$ & $(0.0207)$ & $(0.0347)$ \\
\hline \multirow[t]{2}{*}{ Norway } & $11.04^{*}$ & $1.218^{* *}$ & \\
\hline & -6.363 & $(0.501)$ & \\
\hline \multirow[t]{2}{*}{ Spain } & -0.171 & $0.589^{*}$ & $0.146^{* * *}$ \\
\hline & $(0.431)$ & $(0.347)$ & $(0.0470)$ \\
\hline \multirow[t]{2}{*}{ Sweden } & 0.346 & $2.405^{* * *}$ & $-0.0141^{* * *}$ \\
\hline & $(0.726)$ & $(0.630)$ & $(0.00434)$ \\
\hline \multirow[t]{2}{*}{ UK } & $2.193^{* * *}$ & $-0.534^{* * *}$ & 0.0739 \\
\hline & $(0.636)$ & $(0.0652)$ & $(0.0812)$ \\
\hline Observations & 784 & 784 & 784 \\
\hline & 164.4 & 26.28 & 11.90 \\
\hline $\begin{array}{l}\text { F-stat for all instruments jointly signif. } \\
\text { R-squared }\end{array}$ & 0.830 & 0.560 & 0.646 \\
\hline
\end{tabular}

ICT data are not available for Norway. Robust standard errors in parentheses. OLS regression. 
Table 7: Pre-trend analysis: Relationship between robot exposure and previous employment growth (1981-1991)

\begin{tabular}{|c|c|c|c|c|c|c|}
\hline \multicolumn{7}{|c|}{ PANEL A: Employment growth (1981-1991) } \\
\hline & \multicolumn{3}{|c|}{ unweighted } & \multicolumn{3}{|c|}{ weighted } \\
\hline & All & Manuf. & Non-manuf. & All & Manuf. & Non-manuf. \\
\hline Robot exposure per 1000 workers & -0.323 & -1.113 & 0.306 & -0.195 & -0.640 & 0.293 \\
\hline & $(0.449)$ & $(0.771)$ & $(0.412)$ & $(0.617)$ & $(0.779)$ & $(0.506)$ \\
\hline Area FE & $\checkmark$ & $\checkmark$ & $\checkmark$ & $\checkmark$ & $\checkmark$ & $\checkmark$ \\
\hline Manfacturing share '91 & $\checkmark$ & $\checkmark$ & $\checkmark$ & $\checkmark$ & $\checkmark$ & $\checkmark$ \\
\hline Trade exposure & $\checkmark$ & $\checkmark$ & $\checkmark$ & $\checkmark$ & $\checkmark$ & $\checkmark$ \\
\hline Ict exposure & $\checkmark$ & $\checkmark$ & $\checkmark$ & $\checkmark$ & $\checkmark$ & $\checkmark$ \\
\hline Observations & 784 & 784 & 784 & 784 & 784 & 784 \\
\hline R-squared & 0.135 & 0.113 & 0.134 & 0.205 & 0.344 & 0.185 \\
\hline First stage F stat. & 27.56 & 27.56 & 27.56 & 30.23 & 30.23 & 30.23 \\
\hline
\end{tabular}

PANEL B: Employment to working age population ratio (1981-1991)

\begin{tabular}{l|ccc|ccc} 
& \multicolumn{3}{|c|}{ unweighted } & \multicolumn{3}{c}{ weighted } \\
& All & Manuf. & Non-manuf. & All & Manuf. & Non-manuf. \\
\hline \multirow{2}{*}{ Robot exposure per 1000 workers } & -0.0282 & -0.0900 & 0.0618 & 0.0343 & -0.0656 & 0.0999 \\
& $(0.155)$ & $(0.119)$ & $(0.0806)$ & $(0.178)$ & $(0.162)$ & $(0.0894)$ \\
\hline Area FE & $\checkmark$ & $\checkmark$ & $\checkmark$ & $\checkmark$ & $\checkmark$ & $\checkmark$ \\
Manfacturing share '91 & $\checkmark$ & $\checkmark$ & $\checkmark$ & $\checkmark$ & $\checkmark$ & $\checkmark$ \\
Trade exposure & $\checkmark$ & $\checkmark$ & $\checkmark$ & $\checkmark$ & $\checkmark$ & $\checkmark$ \\
Ict exposure & $\checkmark$ & $\checkmark$ & $\checkmark$ & $\checkmark$ & $\checkmark$ & $\checkmark$ \\
\hline Observations & 784 & 784 & 784 & 784 & 784 & 784 \\
R-squared & 0.061 & 0.270 & 0.112 & 0.183 & 0.521 & 0.233 \\
First stage F stat. & 27.56 & 27.56 & 27.56 & 30.23 & 30.23 & 30.23 \\
\hline
\end{tabular}

2SLS regressions. In Panel A the dependent variable is $100 \times$ log difference in employment between 1981 and 1991. In Panel B the dependent variable is $100 \times$ the change in the employment to working age population ratio between 1981 and 1991. Robust standard errors in parentheses. The unit of analysis are LLMs (1991 definition). The regressions always include a constant (not reported). 


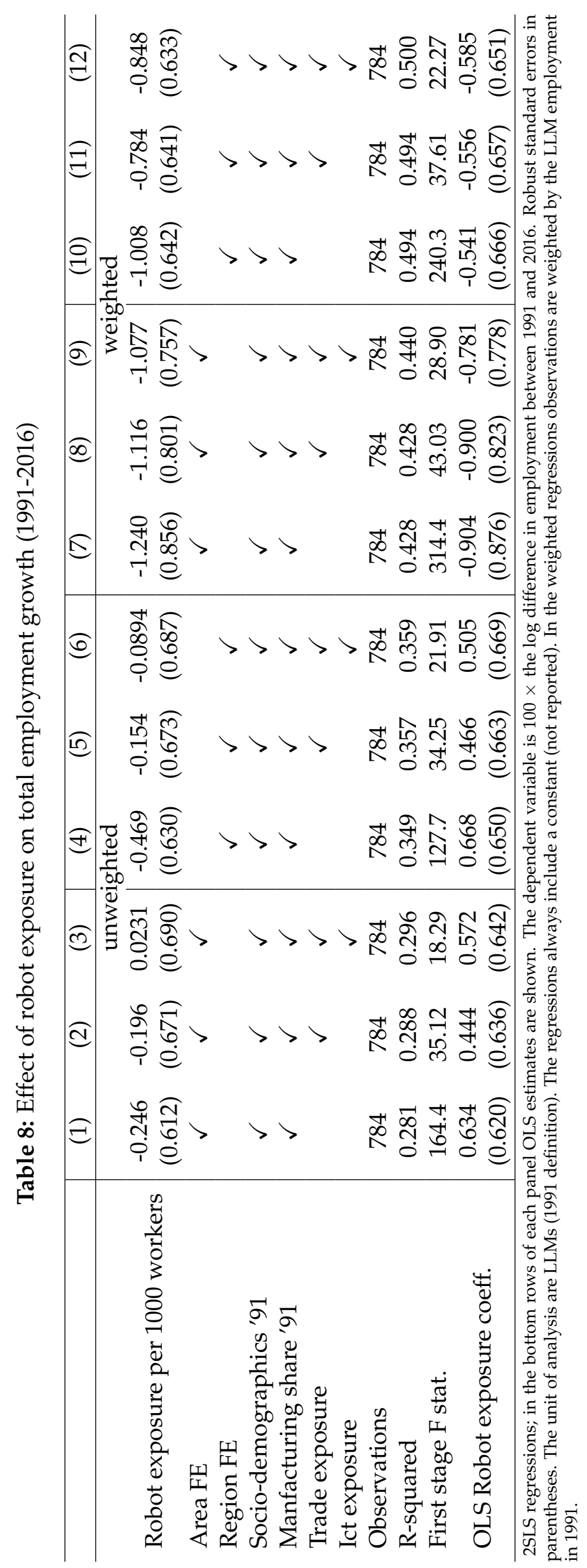




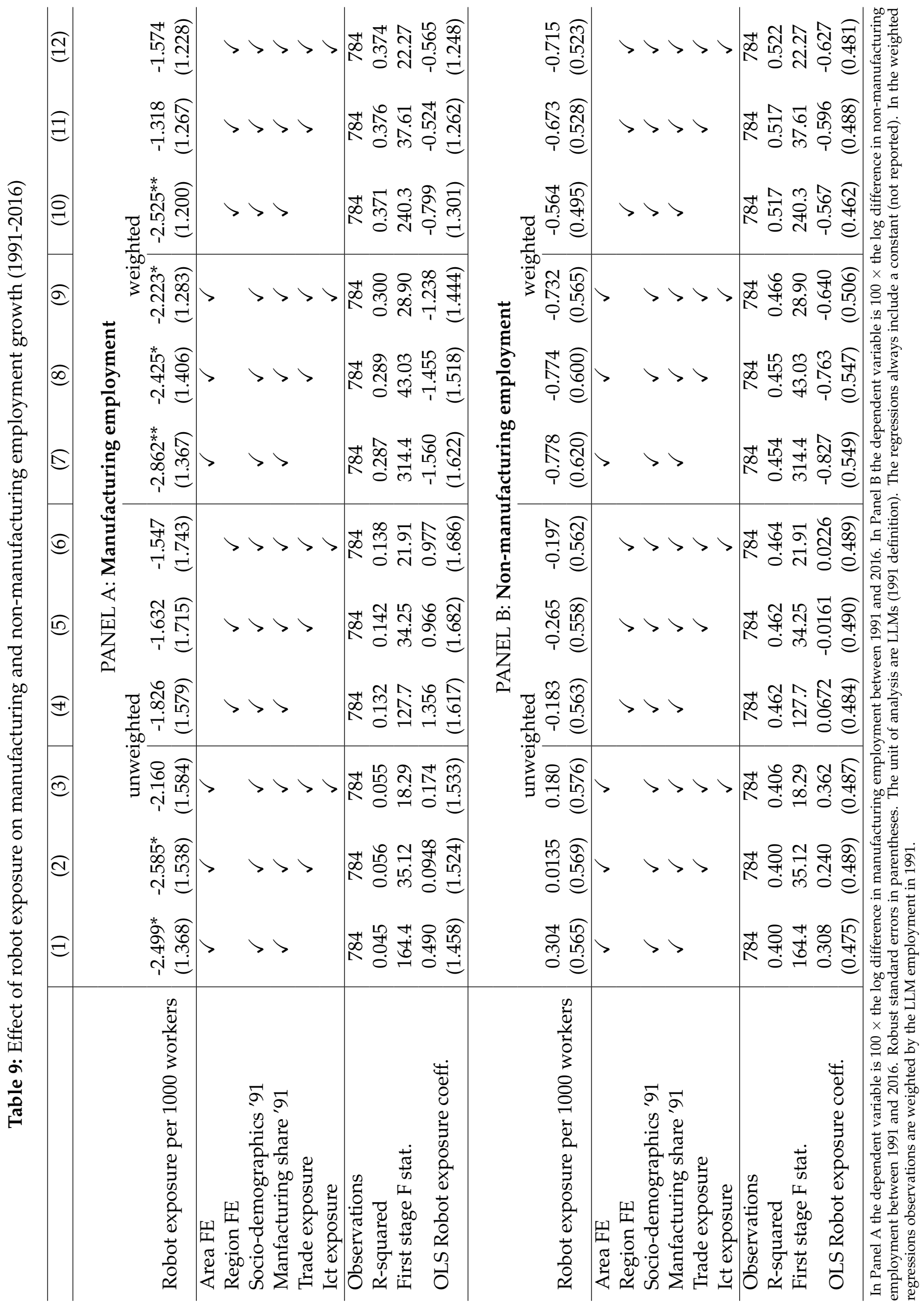




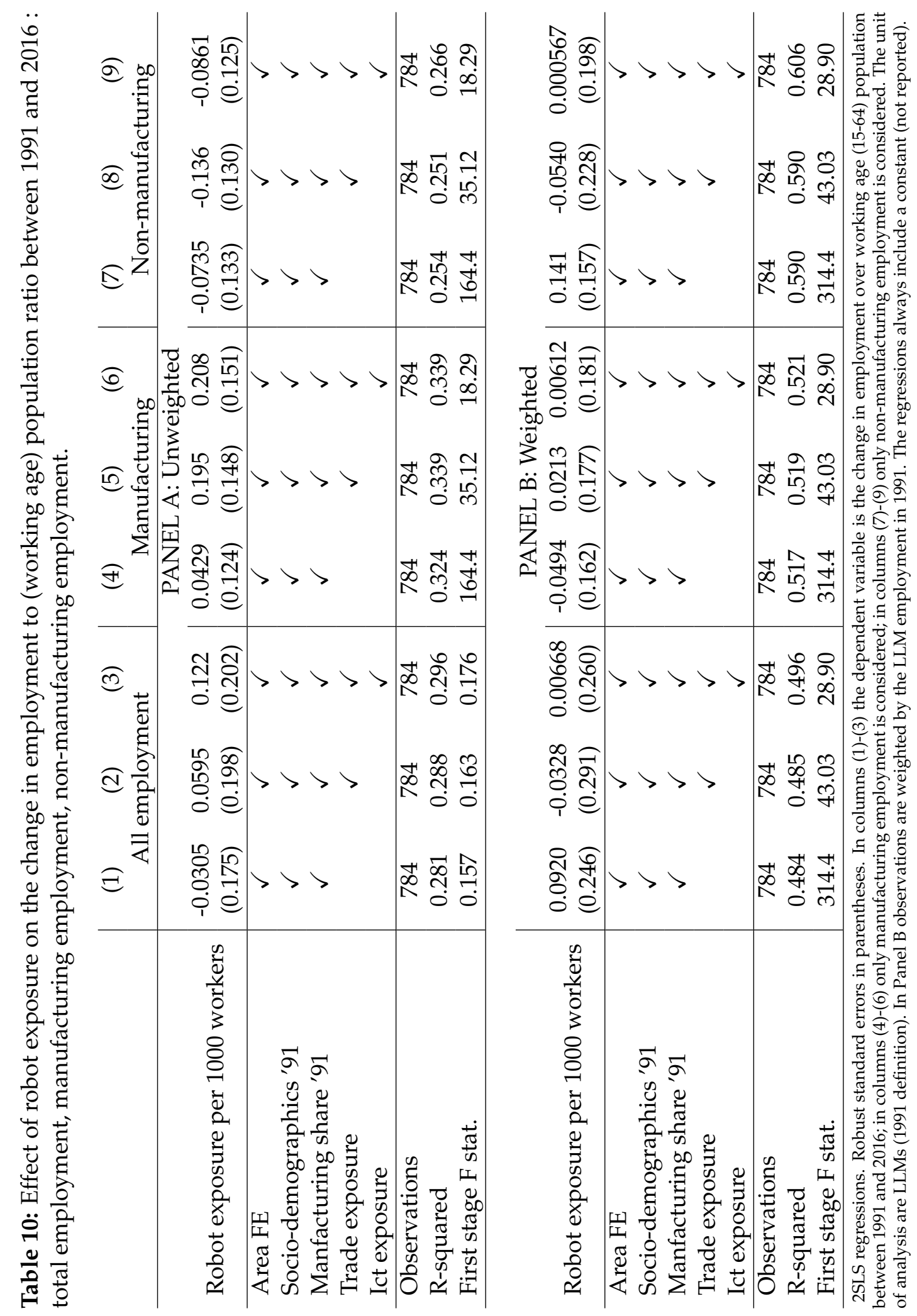


Table 11: Robustness checks: subset of instruments and just identified models

\begin{tabular}{|c|c|c|c|c|c|c|c|c|c|}
\hline & $\begin{array}{l}\text { Non } \\
\text { Euro } \\
\text { Area }\end{array}$ & AVG & DEN & FI & FR & GE & SP & SW & UK \\
\hline \multicolumn{10}{|c|}{ Employment growth } \\
\hline Robot exp & $\begin{array}{l}-0.744 \\
(0.732)\end{array}$ & $\begin{array}{c}0.269 \\
(0.944)\end{array}$ & $\begin{array}{l}-0.746 \\
(1.515)\end{array}$ & $\begin{array}{c}0.205 \\
(0.900)\end{array}$ & $\begin{array}{l}1.068 \\
(1.135)\end{array}$ & $\begin{array}{l}-0.511 \\
(0.829)\end{array}$ & $\begin{array}{l}2.243 \\
(1.378)\end{array}$ & $\begin{array}{l}-0.381 \\
(0.913)\end{array}$ & $\begin{array}{c}1.101 \\
(1.259)\end{array}$ \\
\hline Obs & 784 & 784 & 784 & 784 & 784 & 784 & 784 & 784 & 784 \\
\hline R-squared & 0.254 & 0.216 & 0.109 & 0.285 & 0.243 & 0.221 & 0.148 & 0.172 & 0.130 \\
\hline Fist stage F-stat & 9.082 & 4.249 & 4.287 & 4.926 & 11.88 & 11.26 & 10.97 & 2.311 & 18.22 \\
\hline $\begin{array}{l}\text { Overid. robot instr } \\
\text { (p-value) }\end{array}$ & $\begin{array}{l}3.024 \\
0.554\end{array}$ & & & & & & & & \\
\hline \multicolumn{10}{|c|}{ Manufacturing employment growth } \\
\hline Robot exp & $\begin{array}{l}-2.678 \\
(1.633)\end{array}$ & $\begin{array}{l}-2.356 \\
(1.895)\end{array}$ & $\begin{array}{l}-2.894 \\
(2.843)\end{array}$ & $\begin{array}{l}-1.572 \\
(1.848)\end{array}$ & $\begin{array}{l}-2.122 \\
(2.148)\end{array}$ & $\begin{array}{l}-3.384^{*} \\
(1.788)\end{array}$ & $\begin{array}{l}0.644 \\
(2.347)\end{array}$ & $\begin{array}{l}-2.176 \\
(1.821)\end{array}$ & $\begin{array}{l}-1.605 \\
(2.322)\end{array}$ \\
\hline Obs & 784 & 784 & 784 & 784 & 784 & 784 & 784 & 784 & 784 \\
\hline R-squared & 0.055 & 0.057 & 0.021 & 0.047 & 0.054 & 0.044 & 0.027 & 0.058 & 0.047 \\
\hline Fist stage F-stat & 9.082 & 4.249 & 4.287 & 4.926 & 11.88 & 11.26 & 10.97 & 2.311 & 18.22 \\
\hline $\begin{array}{l}\text { Overid. robot instr } \\
\text { (p-value) }\end{array}$ & $\begin{array}{l}7.600 \\
0.107\end{array}$ & & & & & & & & \\
\hline \multicolumn{10}{|c|}{ Non manufacturing employment growth } \\
\hline Robot exp & $\begin{array}{l}-0.202 \\
(0.669)\end{array}$ & $\begin{array}{c}1.037 \\
(0.841)\end{array}$ & $\begin{array}{l}-0.287 \\
(1.370)\end{array}$ & $\begin{array}{c}0.509 \\
(0.826)\end{array}$ & $\begin{array}{l}1.903^{*} \\
(1.062)\end{array}$ & $\begin{array}{c}0.372 \\
(0.728)\end{array}$ & $\begin{array}{l}2.456^{* *} \\
(1.207)\end{array}$ & $\begin{array}{c}0.243 \\
(0.839)\end{array}$ & $\begin{array}{l}1.965^{*} \\
(1.156)\end{array}$ \\
\hline Obs & 784 & 784 & 784 & 784 & 784 & 784 & 784 & 784 & 784 \\
\hline R-squared & 0.364 & 0.317 & 0.317 & 0.398 & 0.351 & 0.333 & 0.280 & 0.241 & 0.243 \\
\hline Fist stage F-stat & 9.082 & 4.249 & 4.287 & 4.926 & 11.88 & 11.26 & 10.97 & 2.311 & 18.22 \\
\hline $\begin{array}{l}\text { Overid. robot instr } \\
\text { (p-value) }\end{array}$ & $\begin{array}{l}1.350 \\
0.853\end{array}$ & & & & & & & & \\
\hline \multicolumn{10}{|c|}{ Change in employment to working age population } \\
\hline Robot exp & $\begin{array}{l}-0.147 \\
(0.212)\end{array}$ & $\begin{array}{c}0.124 \\
(0.293)\end{array}$ & $\begin{array}{l}-0.105 \\
(0.329)\end{array}$ & $\begin{array}{c}0.051 \\
(0.282)\end{array}$ & $\begin{array}{c}0.296 \\
(0.341)\end{array}$ & $\begin{array}{l}-0.019 \\
(0.251)\end{array}$ & $\begin{array}{c}0.482 \\
(0.414)\end{array}$ & $\begin{array}{c}0.030 \\
(0.288)\end{array}$ & $\begin{array}{c}0.290 \\
(0.385)\end{array}$ \\
\hline Obs & 784 & 784 & 784 & 784 & 784 & 784 & 784 & 784 & 784 \\
\hline R-squared & 0.148 & 0.078 & 0.104 & 0.152 & 0.123 & 0.112 & 0.070 & 0.073 & 0.027 \\
\hline Fist stage F-stat & 9.082 & 4.249 & 4.287 & 4.926 & 11.88 & 11.26 & 10.97 & 2.311 & 18.22 \\
\hline $\begin{array}{l}\text { Overid. robot instr } \\
\text { (p-value) }\end{array}$ & $\begin{array}{l}4.851 \\
0.303\end{array}$ & & & & & & & & \\
\hline
\end{tabular}

All models include as (non reported) regressors: a constant, macro-area dummy, socio demographic variables in 1991 as described in Section 2.1, manufacturing share of employment in 1991, Trade and ICT exposure. Growth and changes of the dependent variables refers to the interval 19912016. Robot, trade and ICT exposure are instrumented as described in Section 2.1 for the baseline model but considering a lower set of instruments: in the first column euro area countries (France, Spain, Finland, Germany) are excluded; in columns from second to the last exactly identified regression are considered, starting with a simple cross country average and then considering each country one by one (Norway is missing because ICT data for Norway are not available in our data source). For the over identified regression using non euro area countries we also report the statistics and the corresponding p-value of the over-identification Hansen test for robot instruments. 
Table 12: Summary statistics for the sample of incumbent workers in manufacturing in 1993

\begin{tabular}{lrrrrrrr} 
& Obs & Mean & Std. Dev. & Min & Max & $\begin{array}{c}\text { Sub-group means (1) } \\
\text { low robot }\end{array}$ \\
& & & & & & \multicolumn{1}{c}{$\begin{array}{l}\text { high- } \\
\text { robot }\end{array}$} \\
\hline Foreign & 157,307 & 0.061 & 0.239 & 0.000 & 1.000 & 0.054 & 0.069 \\
Female & 157,308 & 0.330 & 0.470 & 0.000 & 1.000 & 0.425 & 0.220 \\
Blue collar & 157,308 & 0.713 & 0.452 & 0.000 & 1.000 & 0.721 & 0.704 \\
White collar & 157,308 & 0.275 & 0.446 & 0.000 & 1.000 & 0.266 & 0.285 \\
Apprentist & 157,308 & 0.007 & 0.082 & 0.000 & 1.000 & 0.009 & 0.005 \\
Manager & 157,308 & 0.005 & 0.071 & 0.000 & 1.000 & 0.004 & 0.006 \\
Tenure less than 4 yers & 157,308 & 0.298 & 0.457 & 0.000 & 1.000 & 0.299 & 0.297 \\
Age & 157,308 & 31.079 & 5.585 & 22.000 & 41.000 & 30.859 & 31.333 \\
Log(earnings) & 157,308 & 9.917 & 0.647 & 0.498 & 13.459 & 9.841 & 10.005 \\
Part-time & 157,308 & 0.031 & 0.173 & 0.000 & 1.000 & 0.034 & 0.027 \\
Working days & 157,308 & 275.284 & 68.710 & 0.600 & 312.000 & 270.758 & 280.505 \\
Small firm & 157,308 & 0.342 & 0.474 & 0.000 & 1.000 & 0.371 & 0.307 \\
Medium firm & 157,308 & 0.423 & 0.494 & 0.000 & 1.000 & 0.429 & 0.417 \\
Big firm & 157,308 & 0.235 & 0.424 & 0.000 & 1.000 & 0.200 & 0.275 \\
North-West & 157,308 & 0.436 & 0.496 & 0.000 & 1.000 & 0.381 & 0.498 \\
North-East & 157,308 & 0.262 & 0.440 & 0.000 & 1.000 & 0.272 & 0.250 \\
Center & 157,308 & 0.158 & 0.365 & 0.000 & 1.000 & 0.190 & 0.120 \\
South and Islands & 157,308 & 0.144 & 0.352 & 0.000 & 1.000 & 0.156 & 0.131 \\
prov. unemployment rate & 157,308 & 7.880 & 4.392 & 2.638 & 22.000 & 7.888 & 7.871 \\
prov. employment rate & 157,308 & 55.555 & 6.123 & 37.144 & 65.609 & 55.535 & 55.577 \\
\hline Notes: All time-varying characteristics refer to 1993. (1) Sub-groups are defined according to the median value of the robotexposure distribution & & &
\end{tabular}

Table 13: Summary statistics for incumbent workers' outcome variables

\begin{tabular}{lrrrrr} 
Variables & Obs & Mean & Std Dev & Min & Max \\
\hline Cumulated days worked & 157,308 & $4,764.85$ & $2,285.60$ & 0.00 & $12,308.00$ \\
of which: same firm & 157,308 & $2,183.51$ & $2,264.06$ & 0.00 & $7,176.00$ \\
other firm same industry & 157,308 & $1,015.25$ & $1,796.49$ & 0.00 & $7,176.00$ \\
other manufacturing industry & 157,308 & 846.96 & $1,706.88$ & 0.00 & $7,176.00$ \\
outside manufacturing & 157,308 & 719.14 & $1,481.09$ & 0.00 & $7,176.00$ \\
Cumulated earnings (1) & 157,308 & $2,385.46$ & $2,601.08$ & 0.00 & $34,882.20$ \\
of which: same firm & 157,308 & 927.13 & $1,372.32$ & 0.00 & $28,653.24$ \\
other firm same industry & 157,308 & 525.54 & $1,382.05$ & 0.00 & $28,653.24$ \\
other manufacturing industry & 157,308 & 485.38 & $1,488.51$ & 0.00 & $28,653.24$ \\
outside manufacturing & 157,308 & 447.42 & $1,504.22$ & 0.00 & $28,653.24$ \\
Average wage log (2) & 154,163 & 451.15 & 50.20 & 100.52 & 943.92 \\
same firm & 137,378 & 446.00 & 43.60 & -267.71 & 943.92 \\
other firm same industry & 61,744 & 455.01 & 54.73 & -290.29 & $1,002.32$ \\
other manufacturing industry & 52,496 & 451.24 & 52.74 & -345.08 & $1,075.14$ \\
outside manufacturing & 60,253 & 439.50 & 56.16 & -184.60 & $1,013.24$ \\
\hline
\end{tabular}

Outcomes are taken from 1994 to 2016. - (1) Cumulated earnings are computed as $100 \times$ the ratio between cumulated real gross earnings and real gross earnings in the base year. Real earnings are at 2015 constant prices using the consumer price index.- (2) Average wage is computed as the $100 \times$ the $\log$ of the ratio between cumulated real gross earnings and cumulated days worked. 
Table 14: Individual adjustment to robot exposure

\begin{tabular}{|c|c|c|c|c|}
\hline & \multicolumn{4}{|c|}{ Panel A: cumulated days worked } \\
\hline \multirow{3}{*}{ Robot exposure per 1000 workers } & (a) & (b) & $(\mathrm{c})$ & $(\mathrm{d})$ \\
\hline & $22.45^{* * *}$ & $12.15^{* * *}$ & $10.18^{* * *}$ & $9.906^{* * *}$ \\
\hline & $(2.931)$ & $(1.773)$ & $(1.530)$ & $(1.573)$ \\
\hline Observations & 146202 & 146201 & 146201 & 146201 \\
\hline R-squared & 0.010 & 0.198 & 0.206 & 0.219 \\
\hline \multirow[t]{2}{*}{ Controls } & $\begin{array}{c}\text { Trade exposure } \\
\text { ICT exposure }\end{array}$ & + Worker & + Firm & + Geo \\
\hline & \multicolumn{4}{|c|}{ Panel B: cumulated earnings (1) } \\
\hline \multirow{3}{*}{ Robot exposure per 1000 workers } & (a) & (b) & $(\mathrm{c})$ & $(\mathrm{d})$ \\
\hline & $9.218^{* * *}$ & $8.171^{* * *}$ & $4.959^{* *}$ & $4.901^{* * *}$ \\
\hline & $(3.111)$ & $(2.589)$ & $(2.067)$ & $(1.692)$ \\
\hline Observations & 146202 & 146201 & 146201 & 146201 \\
\hline R-squared & 0.003 & 0.159 & 0.171 & 0.182 \\
\hline \multirow[t]{2}{*}{ Controls } & $\begin{array}{l}\text { Trade exposure } \\
\text { ICT exposure }\end{array}$ & + Worker & + Firm & + Geo \\
\hline & \multicolumn{4}{|c|}{ Panel C: log average wage (2) } \\
\hline \multirow{3}{*}{ Robot exposure per 1000 workers } & (a) & (b) & (c) & (d) \\
\hline & $0.386^{* * *}$ & $0.0692^{*}$ & 0.0148 & 0.0244 \\
\hline & $(0.109)$ & $(0.0398)$ & $(0.0415)$ & $(0.0345)$ \\
\hline Observations & 143215 & 143214 & 143214 & 143214 \\
\hline R-squared & 0.026 & 0.513 & 0.522 & 0.532 \\
\hline Controls & $\begin{array}{c}\text { Trade exposure } \\
\text { ICT exposure }\end{array}$ & + Worker & + Firm & + Geo \\
\hline
\end{tabular}

In Panel A the dependent variable is the cumulated number of days worked between 1994 and 2016; in Panel B the dependent variable is the cumulated real gross earnings between 1994 and 2016 over real gross earnings in 1993 and multiplied by 100. In Panel $C$ the dependent variable is $100 \times \log$ of the average wage, where the average wage is given by cumulated real gross earnings over cumulated working days between 1994 and 2016. Real earnings are at 2015 constant prices using the consumer price index. The estimates are from model (8) and obtained by 2SLS instrumenting the endogenous variables robot exposure, trade exposure and ICT exposure. Instruments are derived from variation in other advanced countries as shown in Section 2. In column (a) only robot, trade and ICT exposure are included as explanatory variabiles, besides a constant. In column (b) worker level controls are added: dummy variables for female, being born abroad, and the following variables taken at the base year: a coarse code of occupation dummies ("blue collar", "white collar", "apprentice", "manager"), a full set of year dummies for age, a dummy for tenures lower than three years, a dummy for part-time jobs, log earnings and days worked. In column (c) we add controls for firm size by adding dummy based on the average number of employees in 1993. In column (d) geographical controls are added including firm region dummy, working region dummy, the employment and unemployment rate in the working province. In all regressions standard errors are clustered at the IFR sector and province level and shown in parentheses. Levels of significance: $1 \% * * *, 5 \% * *, 10 \% *$. 
Table 15: Individual adjustment to robot exposure by workers' mobility across employers

\begin{tabular}{|c|c|c|c|c|c|}
\hline & \multicolumn{5}{|c|}{ Panel A: cumulated days worked } \\
\hline & (a) & (b) & (c) & $(d)$ & (e) \\
\hline Robot exposure per 1000 workers & $\begin{array}{c}9.906^{* * *} \\
(1.573)\end{array}$ & $\begin{array}{c}20.73^{* * *} \\
(2.455)\end{array}$ & $\begin{array}{c}-6.562^{* * *} \\
(2.200)\end{array}$ & $\begin{array}{l}-0.154 \\
(1.586)\end{array}$ & $\begin{array}{c}-4.111^{* * *} \\
(1.512)\end{array}$ \\
\hline \multirow{4}{*}{$\begin{array}{l}\text { Observations } \\
\text { R-squared } \\
\text { Employer }\end{array}$} & 146201 & 146201 & 146201 & 146201 & 146201 \\
\hline & 0.219 & 0.131 & 0.032 & 0.042 & 0.041 \\
\hline & $\begin{array}{l}\text { All em- } \\
\text { ployers }\end{array}$ & $\begin{array}{l}\text { Same } \\
\text { firm }\end{array}$ & $\begin{array}{l}\text { Other } \\
\text { firm } \\
\text { same } \\
\text { industry }\end{array}$ & $\begin{array}{l}\text { Other } \\
\text { manuf. } \\
\text { industry }\end{array}$ & $\begin{array}{l}\text { Non } \\
\text { manuf. }\end{array}$ \\
\hline & \multicolumn{5}{|c|}{ Panel B: cumulated earnings } \\
\hline & (a) & (b) & (c) & $(d)$ & (e) \\
\hline Robot exposure per 1000 workers & $\begin{array}{c}4.901^{* * *} \\
(1.692)\end{array}$ & $\begin{array}{c}11.66^{* * *} \\
(1.184)\end{array}$ & $\begin{array}{l}-3.263^{*} \\
(1.696)\end{array}$ & $\begin{array}{l}-0.380 \\
(1.046)\end{array}$ & $\begin{array}{c}-3.113^{* *} \\
(1.484)\end{array}$ \\
\hline \multirow{5}{*}{$\begin{array}{l}\text { Observations } \\
\text { R-squared } \\
\text { Employer }\end{array}$} & 146201 & 146201 & 146201 & 146201 & 146201 \\
\hline & 0.182 & 0.049 & 0.032 & 0.066 & 0.110 \\
\hline & $\begin{array}{l}\text { All em- } \\
\text { ployers }\end{array}$ & $\begin{array}{l}\text { Same } \\
\text { firm }\end{array}$ & $\begin{array}{l}\text { Other } \\
\text { firm } \\
\text { same } \\
\text { industry }\end{array}$ & $\begin{array}{l}\text { Other } \\
\text { manuf. } \\
\text { industry }\end{array}$ & $\begin{array}{l}\text { Non } \\
\text { manuf. }\end{array}$ \\
\hline & \multicolumn{5}{|c|}{ Panel C: log average wage } \\
\hline & (a) & (b) & (c) & (d) & (e) \\
\hline \multirow[t]{2}{*}{ Robot exposure per 1000 workers } & 0.0244 & $0.113^{* * *}$ & $0.122^{* * *}$ & 0.0322 & -0.111 \\
\hline & $(0.0345)$ & $(0.0325)$ & $(0.0417)$ & $(0.0320)$ & $(0.0706)$ \\
\hline Observations & 143214 & 127716 & 56528 & 49743 & 56330 \\
\hline R-squared & 0.532 & 0.571 & 0.520 & 0.445 & 0.341 \\
\hline Employer & $\begin{array}{l}\text { All em- } \\
\text { ployers }\end{array}$ & $\begin{array}{l}\text { Same } \\
\text { firm }\end{array}$ & $\begin{array}{l}\text { Other } \\
\text { firm } \\
\text { same } \\
\text { industry }\end{array}$ & $\begin{array}{l}\text { Other } \\
\text { manuf. } \\
\text { industry }\end{array}$ & $\begin{array}{l}\text { Non } \\
\text { manuf. }\end{array}$ \\
\hline
\end{tabular}

In Panel A the dependent variable is the cumulated number of days worked between 1994 and 2016; in Panel B the dependent variable is the cumulated real gross earnings between 1994 and 2016 over real gross earnings in 1993 and multiplied by 100 . In Panel $C$ the dependent variable is $100 \times \log$ of the average wage, where the average wage is given by cumulated real gross earnings over cumulated working days between 1994 and 2016. Real earnings are at 2015 constant prices using the consumer price index. The estimates are from model (8) and obtained by 2SLS instrumenting the endogenous variables robot exposure, trade exposure and ICT exposure. Instruments are derived from variation in other advanced countries as shown in Section 2. In each panel, in column (a) the outcome is cumulated irrespective of the employer; in column (b) it is cumulated only when it occurred in the same firm where the worker was employed in the base year; in panel (c) it is cumulated only when it occurred in other firms in the same manufacturing industry; in column (d) it is cumulated only when it occurred in other manufacturing industries, while in column (e) it is cumulated only when it occurred outside of manufacturing. Control variables also include: dummy variables for female, being born, and the following variables taken at the base year: a coarse code of occupation dummies ("blue collar", "white collar", "apprentice", "manager"), a full set of year dummies for age, a dummy for tenures lower than three years, a dummy for part-time jobs, log earnings and days worked; firm size (given by the average number of employees in the initial year); dummies for firm region and working region, employment and unemployment rates in the working province. In all regressions standard errors are clustered at the IFR sector and province level and shown in parentheses. Levels of significance: $1 \% * *, 5 \% * *, 10 \% *$. 
Table 16: Heterogeneity in individual adjustment to robot exposure

\begin{tabular}{|c|c|c|c|c|c|c|}
\hline & \multicolumn{2}{|c|}{ Days } & \multicolumn{2}{|c|}{ Earnings } & \multicolumn{2}{|c|}{ Wage } \\
\hline & All firms & Original firm & All firms & Original firm & All firms & Original firm \\
\hline \multicolumn{7}{|c|}{ By occupation class (ref. cat.: blue collar) } \\
\hline \multirow{2}{*}{ Robot exposure } & $8.883^{* * *}$ & $21.30^{* * *}$ & 1.990 & $11.06^{* * *}$ & -0.0528 & $0.0554^{*}$ \\
\hline & $(1.793)$ & $(2.299)$ & $(1.561)$ & $(1.316)$ & $(0.0333)$ & $(0.0300)$ \\
\hline \multirow{2}{*}{ Robot exp $\times$ White collar } & $-4.279 *$ & $-5.729 *$ & 3.814 & -0.596 & $0.184^{* * *}$ & $0.137^{* * *}$ \\
\hline & $(2.354)$ & (3.119) & $(3.346)$ & $(2.721)$ & $(0.0606)$ & $(0.0435)$ \\
\hline \multirow{2}{*}{ Robot exp $\times$ Manager } & 2.293 & -13.29 & $50.52^{* * *}$ & 11.80 & $1.082^{* * *}$ & 0.509 \\
\hline & $(7.237)$ & $(8.514)$ & $(18.19)$ & $(13.07)$ & $(0.276)$ & $(0.320)$ \\
\hline \multirow{2}{*}{ Robot exp $\times$ Apprentice } & 7.220 & $-32.53^{* * *}$ & 14.29 & $-12.42^{* * *}$ & -0.221 & -0.163 \\
\hline & (11.93) & $(9.283)$ & $(13.29)$ & $(4.268)$ & $(0.146)$ & $(0.157)$ \\
\hline Observations & 146201 & 146201 & 146201 & 146201 & 143214 & 127716 \\
\hline R-squared & 0.221 & 0.132 & 0.183 & 0.050 & 0.533 & 0.572 \\
\hline \multicolumn{7}{|l|}{ By gender (ref. cat.: male) } \\
\hline \multirow{2}{*}{ Robot exp } & $6.514^{* * *}$ & $18.53^{* * *}$ & 3.171 & $10.32^{* * *}$ & 0.00846 & $0.0895^{* *}$ \\
\hline & $(1.636)$ & $(2.602)$ & (2.055) & $(1.252)$ & $(0.0424)$ & $(0.0371)$ \\
\hline \multirow{2}{*}{ Robot exp $\times$ Female } & $4.830^{* *}$ & 3.843 & 1.099 & $2.478^{* *}$ & -0.00965 & 0.0349 \\
\hline & $(2.355)$ & (3.174) & $(2.843)$ & $(1.217)$ & $(0.0511)$ & $(0.0321)$ \\
\hline Observations & 146201 & 146201 & 146201 & 146201 & 143214 & 127716 \\
\hline R-squared & 0.221 & 0.132 & 0.183 & 0.050 & 0.532 & 0.571 \\
\hline \multicolumn{7}{|l|}{ By age (ref. cat.: $2^{\text {nd }}$ tercile) } \\
\hline \multirow[t]{2}{*}{ Robot exp } & $8.066^{* * *}$ & $21.62^{* * *}$ & $4.880^{*}$ & $12.48^{* * *}$ & 0.0384 & $0.110^{* * *}$ \\
\hline & $(1.629)$ & $(2.666)$ & $(2.574)$ & $(1.355)$ & $(0.0405)$ & $(0.0353)$ \\
\hline \multirow[t]{2}{*}{ Robot exp $\times$ Young } & 1.544 & -1.424 & -2.584 & $-2.380^{* *}$ & $-0.0801^{* *}$ & $-0.0406^{*}$ \\
\hline & $(1.580)$ & $(2.006)$ & $(2.704)$ & $(1.062)$ & $(0.0385)$ & $(0.0226)$ \\
\hline \multirow[t]{2}{*}{ Robot exp $\times$ Old } & -2.917 & $-5.473^{* *}$ & -1.838 & $-2.483^{* *}$ & -0.0171 & 0.00453 \\
\hline & $(2.091)$ & $(2.154)$ & $(3.050)$ & $(1.149)$ & $(0.0288)$ & $(0.0226)$ \\
\hline Observations & 146201 & 146201 & 146201 & 146201 & 143214 & 127716 \\
\hline R-squared & 0.221 & 0.132 & 0.183 & 0.050 & 0.532 & 0.571 \\
\hline \multicolumn{7}{|c|}{ By initial earnings (ref. cat.: $2^{\text {nd }}$ tercile) } \\
\hline \multirow[t]{2}{*}{ Robot exp } & $5.584^{* * *}$ & $18.53^{* * *}$ & -0.124 & $7.963^{* * *}$ & 0.0198 & $0.0785^{* * *}$ \\
\hline & $(1.508)$ & $(2.662)$ & $(1.698)$ & $(1.359)$ & $(0.0266)$ & $(0.0289)$ \\
\hline \multirow[t]{2}{*}{ Robot exp $\times$ Low } & $4.202^{*}$ & 2.410 & 8.468 & $8.792^{*}$ & $-0.0727^{*}$ & 0.00937 \\
\hline & $(2.308)$ & $(4.164)$ & $(5.420)$ & $(5.073)$ & $(0.0383)$ & $(0.0485)$ \\
\hline \multirow[t]{2}{*}{ Robot exp $\times$ High } & 0.320 & -1.969 & 2.420 & 0.834 & 0.00595 & 0.0248 \\
\hline & $(1.547)$ & $(3.229)$ & $(2.459)$ & $(1.793)$ & $(0.0491)$ & $(0.0332)$ \\
\hline Observations & 146201 & 146201 & 146201 & 146201 & 143214 & 127716 \\
\hline R-squared & 0.226 & 0.139 & 0.221 & 0.132 & 0.555 & 0.591 \\
\hline \multicolumn{7}{|c|}{ By Macro-Area (ref. cat.: Center-North) } \\
\hline \multirow[t]{2}{*}{ Robot exp } & $4.704^{* * *}$ & $18.59^{* * *}$ & 1.528 & $10.51^{* * *}$ & -0.00309 & $0.0952^{* *}$ \\
\hline & $(1.132)$ & $(2.349)$ & $(1.599)$ & $(1.141)$ & $(0.0379)$ & $(0.0385)$ \\
\hline \multirow[t]{2}{*}{ Robot $\exp \times$ South } & $15.76^{* * *}$ & 4.594 & $10.15^{* *}$ & 2.175 & 0.0501 & 0.0146 \\
\hline & $(4.531)$ & (7.689) & $(4.847)$ & $(3.672)$ & $(0.0640)$ & $(0.0605)$ \\
\hline Observations & 146201 & 146201 & 146201 & 146201 & 143214 & 127716 \\
\hline R-squared & 0.221 & 0.132 & 0.183 & 0.050 & 0.532 & 0.571 \\
\hline
\end{tabular}

The interacted dummy variables are also included in level. In each model, control variables also include covariates as in Table 15 . In all regressions standard errors are clustered at the IFR sector and province level and shown in parentheses. Levels of significance: $1 \%^{* * *}, 5 \%{ }^{* *}, 10 \% *$. 
Table 17: Blue collars adjustment to robot exposure by mobility in occupation qualification (dep. var.: cumulated days worked)

\begin{tabular}{lccc|ccc} 
& \multicolumn{3}{c|}{ All employers } & \multicolumn{3}{c}{ Original Firm } \\
& Both & Not as Blue Coll. & As Blue Coll. & Both & Not as Blue Coll. & As Blue Coll. \\
\hline & $(\mathrm{a})$ & $(\mathrm{b})$ & $(\mathrm{c})$ & $(\mathrm{d})$ & $(\mathrm{e})$ & $(\mathrm{e})$ \\
Robot $\exp$ & $9.867^{* * *}$ & $-3.882^{* * *}$ & $13.75^{* * *}$ & $19.37^{* * *}$ & $-0.787^{*}$ & $20.16^{* * *}$ \\
Observations & $(1.658)$ & $(0.752)$ & $(1.694)$ & $(2.202)$ & $(0.413)$ & $(2.146)$ \\
R-squared & 108241 & 108241 & 108241 & 108241 & 108241 & 108241 \\
Mean days worked & 0.241 & 0.036 & 0.178 & 0.152 & 0.022 & 0.139 \\
\hline
\end{tabular}

The dependent variable is the cumulated number of days worked between 1994 and 2016 distinguished according to whether they were cumulated at the original firm or not and remaining occupied as blue collar or not. The estimates are obtained by 2SLS instrumenting the endogenous variables robot exposure, trade exposure, ICT exposure. Instruments are derived from variation in other advanced countries as shown in Section 2.Control variables also include: dummy variables for female, being born, and the following variables taken at the base year: a full set of year dummies for age, a dummy for tenures lower than 4 year, a dummy for part-time jobs, log earnings and days worked; firm size (given by the average number of employees in the initial year); dummies for firm region and working region, employment and unemployment rates in the working province. In all regressions standard errors are clustered at the IFR sector and province level and shown in parentheses. Levels of significance: $1 \%{ }^{* *}, 5 \% * *, 10 \%$. 
Table 18: Effect of robot exposure on entrants' share (1993-2016)

\begin{tabular}{lcccccc}
\hline & $(\mathrm{a})$ & $(\mathrm{b})$ & $(\mathrm{c})$ & $(\mathrm{d})$ & $(\mathrm{e})$ & $(\mathrm{f})$ \\
& $-0.455^{* * *}$ & $-0.502^{* * *}$ & $-0.478^{* * *}$ & $-0.443^{* * *}$ & $-0.490^{* * *}$ & $-0.484^{* * *}$ \\
Robot exposure per 1000 workers & $(0.142)$ & $(0.161)$ & $(0.164)$ & $(0.151)$ & $(0.165)$ & $(0.165)$ \\
Geog. FE & Area & Area & Area & Reg & Reg & Reg \\
Socio-demographics '91 & $\checkmark$ & $\checkmark$ & $\checkmark$ & $\checkmark$ & $\checkmark$ & $\checkmark$ \\
Manufacturing share '91 & $\checkmark$ & $\checkmark$ & $\checkmark$ & $\checkmark$ & $\checkmark$ & $\checkmark$ \\
Trade exposure & & $\checkmark$ & $\checkmark$ & & $\checkmark$ & $\checkmark$ \\
ICT exposure & & & $\checkmark$ & & & $\checkmark$ \\
\hline Obs & 10604 & 10604 & 10604 & 10604 & 10604 & 10604 \\
R-squared & 0.013 & 0.017 & 0.017 & 0.016 & 0.019 & 0.018 \\
Fist stage F & 706.8 & 693.5 & 21.86 & 659.1 & 587.4 & 14.09 \\
\hline unweighted estimates & $-0.854^{* * *}$ & $-0.852^{* * *}$ & $-0.849^{* * *}$ & $-0.857^{* * *}$ & $-0.854^{* * *}$ & $-0.852^{* * *}$ \\
& $(0.165)$ & $(0.168)$ & $(0.169)$ & $(0.165)$ & $(0.169)$ & $(0.169)$ \\
\hline
\end{tabular}

Notes: Robust standard errors clustered at the LLM in parentheses. The unit of analysis are IFR sector \& LLMs (1991 definition) cells. The dependent variable is the change in the share of entrants in the IFR sector out of total entrants in the LLM between 1993 and 2016 (per cent). The regressions always include a constant (not reported). Robot, trade, and ICT exposure are defined in Section 2 and 3 and refers to the span up to 2016. ICT shock is defined at the LLM level. Regressions are by 2SLS, where Robot, Trade and Ict exposure are instrumented as explained in Section 2. Observations weighted by 1991 employment. In the last rows unweighted estimates are reported.

Table 19: Effect of robot exposure on reentrants' share (1993-2016)

\begin{tabular}{lcccccc}
\hline & $(\mathrm{a})$ & $(\mathrm{b})$ & $(\mathrm{c})$ & $(\mathrm{d})$ & $(\mathrm{e})$ & $(\mathrm{f})$ \\
& $-0.375^{* * *}$ & $-0.424^{* * *}$ & $-0.413^{* * *}$ & $-0.392^{* * *}$ & $-0.441^{* * *}$ & $-0.437^{* * *}$ \\
Robot exposure per 1000 workers & $(0.136)$ & $(0.137)$ & $(0.138)$ & $(0.138)$ & $(0.141)$ & $(0.139)$ \\
Geog. FE & Area & Area & Area & Reg & Reg & Reg \\
Socio-demographics '91 & $\checkmark$ & $\checkmark$ & $\checkmark$ & $\checkmark$ & $\checkmark$ & $\checkmark$ \\
Manufacturing share '91 & $\checkmark$ & $\checkmark$ & $\checkmark$ & $\checkmark$ & $\checkmark$ & $\checkmark$ \\
Trade exposure & & $\checkmark$ & $\checkmark$ & & $\checkmark$ & $\checkmark$ \\
ICT exposure & & & $\checkmark$ & & & $\checkmark$ \\
\hline Obs & 10604 & 10604 & 10604 & 10604 & 10604 & 10604 \\
R-squared & 0.011 & 0.011 & 0.011 & 0.011 & 0.012 & 0.011 \\
Fist stage F & 706.8 & 693.5 & 21.86 & 659.1 & 587.4 & 14.09 \\
\hline unweighted estimates & $-0.694^{* * *}$ & $-0.626^{* * *}$ & $-0.621^{* * *}$ & $-0.691^{* * *}$ & $-0.623^{* * *}$ & $-0.619^{* * *}$ \\
& $(0.187)$ & $(0.188)$ & $(0.189)$ & $(0.187)$ & $(0.188)$ & $(0.188)$ \\
\hline
\end{tabular}

Notes: Robust standard errors clustered at the LLM in parentheses. The unit of analysis are IFR sector \& LLMs (1991 definition) cells. The dependent variable is the change in the share of entrants in the IFR sector out of total entrants in the LLM between 1993 and 2016 (per cent). The regressions always include a constant (not reported). Robot, trade, and ICT exposure are defined in Section 2 and 3 and refers to the span up to 2016. ICT shock is defined at the LLM level. Regressions are by 2SLS, where Robot, Trade and Ict exposure are instrumented as explained in Section 2. Observations weighted by 1991 employment. In the last rows unweighted estimates are reported. 


\section{A More details on data and dataset construction}

\section{A.1 IFR data}

As mentioned in Section 3, according to the International Organization for Standardization (ISO) definition 8373 a robot is an automatically controlled, reprogrammable, multi-purpose manipulator programmable in three or more axes, which may be either fixed in place or mobile for use in industrial automation applications. Robots are hence fully autonomous machines that do not need a human operator and can be programmed to perform several manual tasks such as welding, painting, assembly, handling materials, or packaging. Textile looms, elevators, cranes, or transportation bands are not industrial robots as they have a unique purpose, cannot be reprogrammed to perform other tasks, and/or require a human operator (see IFR (2018) for further details). The IFR estimates of operational stock is based on the assumption of an average service life of 12 years. As discussed in Borjas and Freeman (2019), there are no information on prices nor on the specific quality features of each robot, thus preventing the possibility of constructing quality-adjusted measures.

Given constraint on data availability and the necessity to consider a consistent level of aggregation across countries and years, data are taken remaining at the upper industry level whenever at the lower levels there are values classified as "unspecified" for some or all countries: 17 main sectoral groups remain, as listed in the Table 1, out of which 11 belong to manufacturing. The 18th category is labelled as "unspecified sector": as in Acemoglu and Restrepo (2017), its values are attributed to the other sectors proportionally. In the analysis at the LLM level the first two sectors (Agriculture, forestry, fishing and Mining and quarrying) are excluded since for them employment data in 2016 are not available: 15 IFR industry groups $(J=15)$ are hence used, similarly to Carbonero et al. (2018).

\section{A.2 Other macro data}

Trade data are taken from OECD selecting as reporting countries Italy, Germany, France, Spain, Finland, Denmark, Sweden, Norway, United Kingdom. As in in Dauth et al. (2018) the selected partners countries are China and 21 Eastern European/Asian countries that were part of the former Soviet block: Bulgaria, Czech Republic, Hungary, Poland, Romania, Slovakia, Slovenia, Russian Federation, Belarus, Estonia, Latvia, Lithuania, Moldova, Ukraine, Azerbaijan, Georgia, Kazakhstan, Kyrgyzstan, Tajikistan, Turkmenistan, and Uzbekistan.

Exports and imports of goods are collected for the following 31 sectors defined according to ISIC Rev. 4 at the 2-digit level: Crop and animal production, hunting; Forestry and logging; Fishing and aquaculture; Mining of metal ores; Other mining and quarrying; Food products; Beverages; Tobacco products; Textiles; Wearing apparel; Leather and related products; Wood and products of wood and cork, except furniture; Paper and paper products; Printing and reproduction of recorded media; Coke and refined petroleum products; Chemicals and chemical products; Basic pharmaceutical products and pharmaceutical preparations; Rubber and plastics products; Other non-metallic mineral products; Basic metals; Fabricated metal products, except machinery and equipment; Computer, electronic and optical products; Electrical equipment; Machinery and 
equipment n.e.c.; Motor vehicles, trailers and semi-trailers; Other transport equipment; Furniture, other manufacturing; Other activities. Categories coded as "adjustment" and "waste" are dropped, while the "unspecified" category is allocated proportionally across the other classes. Data are collected for years 1993, 2001, 2011 and 2016 and deflated by using the US GDP deflator to express them at constant 2011 US dollars.

Concerning the construction of the ICT exposure, the list of EU KLEMS (2018) industry classes and the resulting ICT exposure are reported in the Table below. For Norway data are not available and so this country cannot be used to construct an instrument for ICT shock. For Italy and Germany data are available only since 1995, so this year is taken as base year for all countries. For UK data start in 1997, so the 1995 value is computed by backward extrapolation based on the slope between 1997 and 2007.

\section{ICT Sectors and exposure}

\begin{tabular}{|c|c|}
\hline EU KLEMS Sector & ICT exposure \\
\hline Telecommunications & 1636 \\
\hline Professional, Scientific, Technical, Ad. & 554 \\
\hline Public Administration And Defence; Comp. & 528 \\
\hline Publishing, Audiovisual And Broadcasting & 291 \\
\hline IT And Other Information Services & 288 \\
\hline Construction & 271 \\
\hline Health And Social Work & 111 \\
\hline Wholesale Trade, Except Of Motor Vehicles & 107 \\
\hline Machinery And Equipment N.E.C. & 95 \\
\hline Education & 92 \\
\hline Financial And Insurance Activities & 85 \\
\hline Transport And Storage & 83 \\
\hline Other Service Activities & 46 \\
\hline Retail Trade, Except Of Motor Vehicles & 46 \\
\hline Textiles, Wearing Apparel, Leather And & 45 \\
\hline Rubber And Plastics Products, And Other & 41 \\
\hline Basic Metals And Fabricated Metal Products & 39 \\
\hline Electrical And Optical Equipments & 38 \\
\hline Real Estate Activities & 36 \\
\hline Electricity, Gas And Water Supply & 26 \\
\hline Chemicals And Chemical Products & 16 \\
\hline Wholesale And Retail Trade And Repair O & 15 \\
\hline Food Products, Beverages And Tobacco & 8 \\
\hline Transport Equipments & 2 \\
\hline Coke And Refined Petroleum Products & 1 \\
\hline Other Manufacturing; Repair And Install. & 1 \\
\hline Activities Of Extraterritorial Organizations & 0 \\
\hline Activities Of Households As Employers; & 0 \\
\hline Wood And Paper Products; Printing & -74 \\
\hline Accommodation And Food Service Activities & -198 \\
\hline
\end{tabular}

Source: EUKLEMS and our computation. Sector classes are according to EUKLEMS data. The ICT exposure is computed as the change in real gross fixed capital formation volume for computing equipment and communication equipment between 1995 and 2014, normalized by sector employment in 1991. 
Employment data at the 2-digit industry level are taken from firm Census data (Censimento generale dell'industria e dei servizi) for years 1981, 1991, 2001 and 2011 and from the Italian Statistical Register of Active Enteprises (Registro statistico delle imprese attive, ASIA) provided by the National Institute of Statistics (Istat) for 2016. In the latter source firms in Agriculture, forestry, fishing and in Mining and quarrying sections are not covered, so these sectors are not conisdered in the empirical analysis at the LLM in every year to keep a consistent definition up to 2016. The dataset do not include public employment (defined according to sect. O of Nace Rev. 2), associations (2-digit code 94), section T activities; section U organizations; public and no-profit institutions.

Two major issues arise in order to create a consistent dataset over time: sector reclassification and geographical unit of analysis. As far as the former is concerned, data at the 2-digit Ateco 2007 (Nace Rev. 2) definition are available for years 2011, 2016. For 1991 and 2001 data were based on Ateco 2002 (Nace Rev. 1.1); in these years, the cross-walk into Ateco 2007 2-digit codes for manufacturing industries implemented by Citino and Linarello (2019) was taken. For industries outside manufacturing and for 1981 data I carried out a cross-walk from the original Ateco codes (Ateco 1991 - Nace Rev. 1 and Ateco 1981 - roughly corresponding to Nace 70) into Ateco 2007 using conversion tables. Although a clear-cut conversion at the 2-digit level is not possible and measurement errors cannot be excluded, discrepancies are generally smoothed when in the next step these codes are collapsed into the broader IFR classes (or EU KLEMS classes for ICT).

About the geographical unit of analysis, as mentioned in Section 2.1, the 1991 local labour markets (in Italian: Sistemi locali del lavoro) definition is considered (in brief: LLM91). Population data for years 1981, 1991, 2001 are taken from Population Census data at the LLM91 level are provided by Istat in the Statistical Atlas of municipalities(Atlante statistico dei comuni), properly aggregating data at the municipality level from Census data. For 2011 Census municipality data are mapped into LLM91 boundaries through a conversion table. The same procedure is followed for 2016 data, taking into account changes due to aggregation of municipalities and/or other variations occurred in recent years. Whenever a new municipality originates from the aggregations of former municipalities belonging to different LLM91, the population of the new municipality is associated to a LLM91 based on population shares according to 2011 Census data.

\section{A.3 Worker-level data}

The data sources for the worker-level analysis are administrative data from the Italian Social Security Institute (INPS). Workers' data come from a dataset based on a sample of privately employed individuals born in two given dates of every month (thus covering about $6.6 \%$ of the universe). In this dataset there is information on individuals' characteristics (e.g.: date and country of birth, gender) and can follow their job spells from 1990 to 2016 tracking the employer, a coarse occupation class (basically blue-collar, white-collar, manager, apprentice), days worked, part-time condition and gross earnings; unfortunately, information on workers' education is not available. It is possible to match each employer to another dataset from INPS covering the universe of Italian firms year by year; from the latter dataset it is possible to recover information on firm characteristics, such as industry at the 2-digit level and average number of employees. Industry classification is available according to both Ateco 2002 (NACE Rev. 1.1) and Ateco 2007 (NACE Rev. 2). Information from 
the employee's dataset is matched with the firm dataset by means of a firm identifier. This identifier refers to the firm and, for firms having more than one plant, does not allow to identify single plants; however in the worker dataset the working province is reported.

In the analysis of incumbent workers, a firm is associated to each worker in the sample that in 1993 had a positive amount of days worked and earnings. When there are more than one firm per worker, I pick up the job with the highest earnings and, if this is not conclusive, I select the job with longest duration. ${ }^{44}$ Then, some refinements are applied in order to eliminate incongruent or impossible data and outliers. Following Dauth et al. (2018), only incumbent workers with at least two years tenure are considered. Workers whose age in 1993 was below 22 years or above 41 years are dropped from the sample; the upper bound is chosen taking into account that their outcomes is measured up to 23 years later, thus excluding individuals that during the analysed period grew older than the conventional working age. Based on data availability, information is gathered on whether the individuals worked for the same firm in 1990 and 1991, to build a control for low tenures. Similarly, control variables are constructed based on information on workers' country of birth, gender and the occupation characteristics in 1993 (occupation class, full time vs part time). ${ }^{45}$ Moreover, the overall gross earnings and days worked in the base year are used as control variables.

The selected workers are followed in their job spells from 1994 to 2016. Data on earnings are deflated according to the annual consumer price index at the national level with 2015 prices. For part-time jobs spells, days worked are weighted by 0.6 to proxy a full time equivalent amount of days. This roughly corresponds to a part-time time schedule of 5 hours a day relative to a full time of 8 hours a day. This weighting was taken into account in selecting the employer-employee match in the base year. As in the reference literature, non-employment spells are considered as periods with zero days worked and zero earnings. Then, days worked and real gross earnings between 1994 and 2016 are collapsed, tracking whether they are cumulated at the original firm, in other firms within the original industry, in other manufacturing industries or outside manufacturing.

In the analysis on entrant shares, the association of each (re)entrant worker to a LLM91 is based on information about the firm location from the matched employer-employee dataset. Whenever an employee has more than one employer I select the employer to which is associated the highest total earnings in the year or, if equal, the highest number of working days. For the residual few cases of persisting ties due to equal earnings and working days in two different employers, the match is randomly selected. Whenever there is only information on firm's zip code, a cross walk from zip code to municipality is carried out; then, each municipality is linked to its LLM91 and data are collapsed at the LLM91 and IFR-industry level.

\footnotetext{
${ }^{44}$ When these two criteria are not conclusive, if the firms belongs to different industries I select the firm belonging to the industry where the worker worked longer in the year, considering all his/her job spells also in other firms. In the extremely residual cases (less than 0.1 per cent) where this is not conclusive again, the firm is assigned randomly.

${ }^{45}$ Whenever for a given selected employer-employee match these features are not unique, I again select values associated to highest earnings, then longest duration, and then, for the extremely residual cases when this is not conclusive one, the choice is randomized.
} 


\section{B LLM analysis: Shorter time intervals and heterogeneity}

In Table 20 a shorter time interval than in the baseline specification is considered. In Panel A the ending year is the Census year 2011, thus still representing a suitable horizon for a long-term analysis. Estimates refer to the baseline model with standard controls and trade and ict exposure, again for the three dimensions of overall, manufacturing and non-manufacturing employment. In every specification, the effect of robot exposure is non-significant, either when considering as outcome employment growth or change in employment to working age population ratio.

In Panel B, the time interval is further shrunk to the Census year 2001. However, in this case results should be taken with higher caution as the interval for robot data is just eight year and it could be too short and unreliable to assess a long-term impact. The coefficient on overall employment is negative, driven by the manufacturing component. As the growth rate of robot was relatively higher in this period before the flattening since mid-2000s, these estimates could suggest that the impact of robots could be related to their speed of diffusion.

In Table 21, possible heterogeneous responses are allowed according to LLM's initial situation with respect to robot intensity and employment share of tradable sectors. In Panel A LLMs are split based on whether the initial robot intensity is above or below (or equal) the median; the initial robot intensity is computed as the weighted average of robot stock per thousands workers, with weights given by the industry employment share. Results show that the effect on total employment is not significantly different between the two groups of LLMs; nonetheless, the negative effect on manufacturing employment seems to concentrate in LLMs where robots were originally more relevant; in these LLMs also $\Delta r o b^{r}$ happened to be higher. ${ }^{46}$ Note however that in these LLMs there is also a relatively more beneficial effect on non-manufacturing employment.

In Panel B of Table 21, the two groups of LLMs are defined depending on employment share in tradable sectors (with the median used again as threshold level). The definition of tradable sectors is based on a 1-digit classification as in Cardi and Restout (2015): according to it, tradable sectors include manufacturing, services of transport, communications, storage, and services of Financial Intermediation. ${ }^{47}$ Results are similar to those in Panel A: no statical difference on the overall effect emerges but there is a negative effect on manufacturing employment concentrated in LLMs with higher tradable sectors' share. The similarity with results in Panel A is not surprising as tradable sectors include the manufacturing sectors where robots are mostly used.

\footnotetext{
${ }^{46}$ In a non reported robustness check it is verified that these original differences are not driving the main results by adding the initial robot intensity as a control in the baseline model. The main results are confirmed.

${ }^{47}$ Using a different definition based on the ratio between the sum of imports and exports over total value added at the 2-digit level does not substantially affect results.
} 


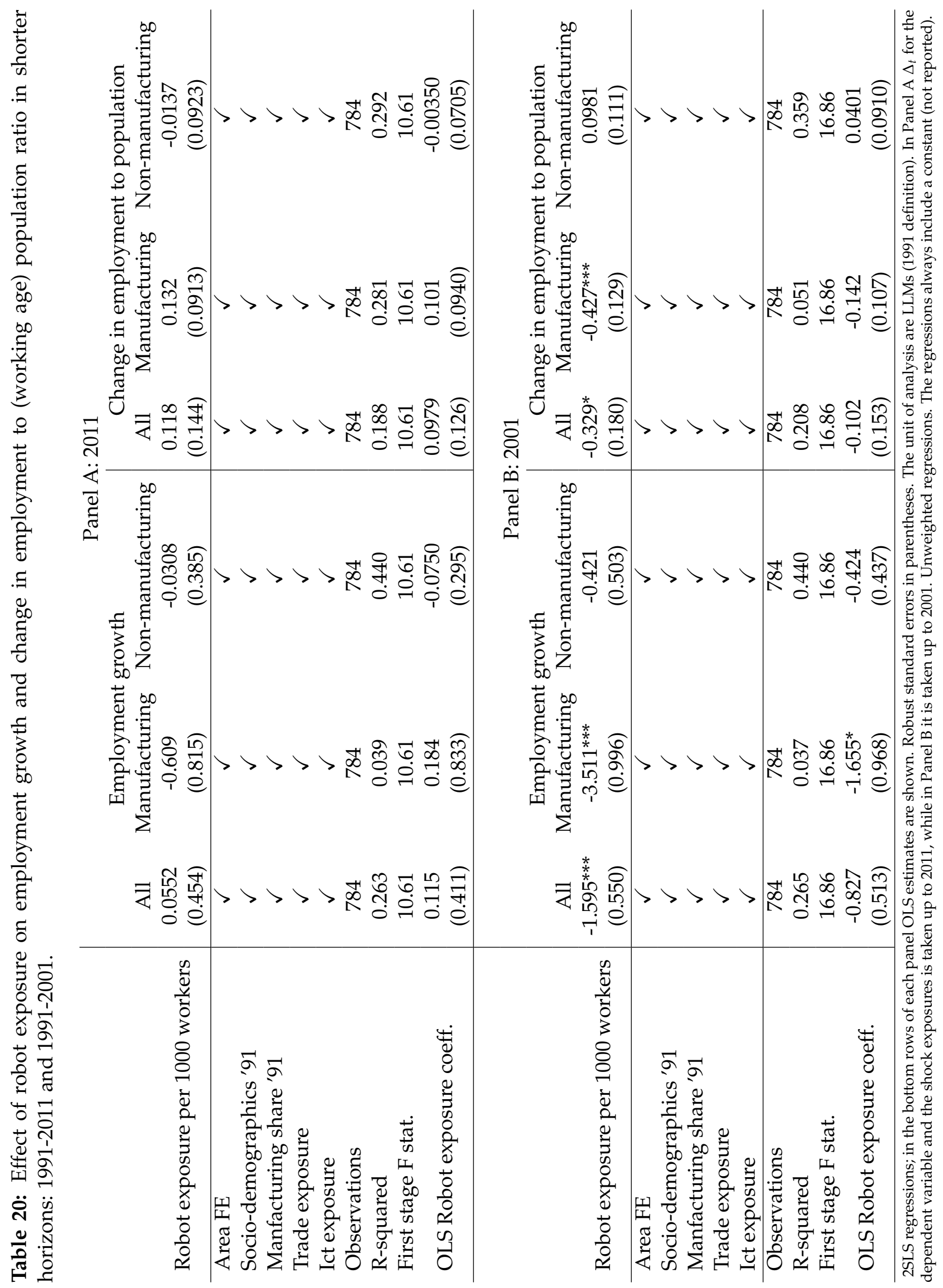


Table 21: Heterogenous effect of exposure to robots

Panel A

By initial robot intensity (1)

\begin{tabular}{l|ccc}
\hline & Overall & Manufact. & Non-manuf. \\
Robot exposure per 1000 workers & -0.993 & 2.507 & -2.035 \\
& $(1.359)$ & $(2.553)$ & $(1.361)$ \\
Robot exp × high initial robot int. & 0.960 & $-4.205^{*}$ & $2.302^{* *}$ \\
Observations & $(1.171)$ & $(2.229)$ & $(1.169)$ \\
R-squared & 784 & 784 & 784 \\
Area FE & 0.296 & 0.064 & 0.408 \\
Socio-demographics '91 & $\checkmark$ & $\checkmark$ & $\checkmark$ \\
Manufacturing share '91 & $\checkmark$ & $\checkmark$ & $\checkmark$ \\
Trade exposure & $\checkmark$ & $\checkmark$ & $\checkmark$ \\
Ict exposure & $\checkmark$ & $\checkmark$ & $\checkmark$ \\
First stage F-stat. & $\checkmark$ & $\checkmark$ & $\checkmark$ \\
\hline
\end{tabular}

Panel B

By inititial employment share in tradable sectors (2)

\begin{tabular}{l|ccc}
\hline & Overall & Manufact. & Non-manuf. \\
Robot exposure per 1000 workers & 0.709 & 4.105 & -0.953 \\
& $(1.636)$ & $(3.274)$ & $(1.612)$ \\
Robot exp × high initial tradable share & -0.803 & $-6.313^{*}$ & 1.103 \\
Observations & $(1.565)$ & $(3.260)$ & $(1.544)$ \\
R-squared & 784 & 784 & 784 \\
Area FE & 0.301 & 0.064 & 0.410 \\
Socio-demographics '91 & $\checkmark$ & $\checkmark$ & $\checkmark$ \\
Manufacturing share '91 & $\checkmark$ & $\checkmark$ & $\checkmark$ \\
Trade exposure & $\checkmark$ & $\checkmark$ & $\checkmark$ \\
Ict exposure & $\checkmark$ & $\checkmark$ & $\checkmark$ \\
First stage F-stat. & $\checkmark$ & $\checkmark$ & $\checkmark$ \\
\hline
\end{tabular}

Robust standard errors in parentheses. (1) Initial robot intensity is defined as the weighted average number of robot per thousand workers with weights given by the IFR industry share in the LLM. The dummy high initial robot intensity is equal to one whenever initial robot intensity is higher than its median value. The dummy variable is also included in level (i.e., non interacted) in the regression. (2) Tradable sectors are defined at 1-digit ISIC rev. 3 as in Cardi and Restout (2015), including total manufacturing, services of transport, communications, storage, and services of Financial Intermediation. Given this definition, we compute the initial employment share in tradable sectors. The dummy high tradable share is equal to 1 whenever it is higher than its median value. The dummy variable is also included in level (i.e., non interacted) in the regression. 